UCRL-ID-121036

\title{
Pre-shot Predictions and Instrumentation of the KUCHEN Experiment
}

\author{
Bill Moran \\ Raymond A. Heinle \\ Philip E. Harben
}

May 1995

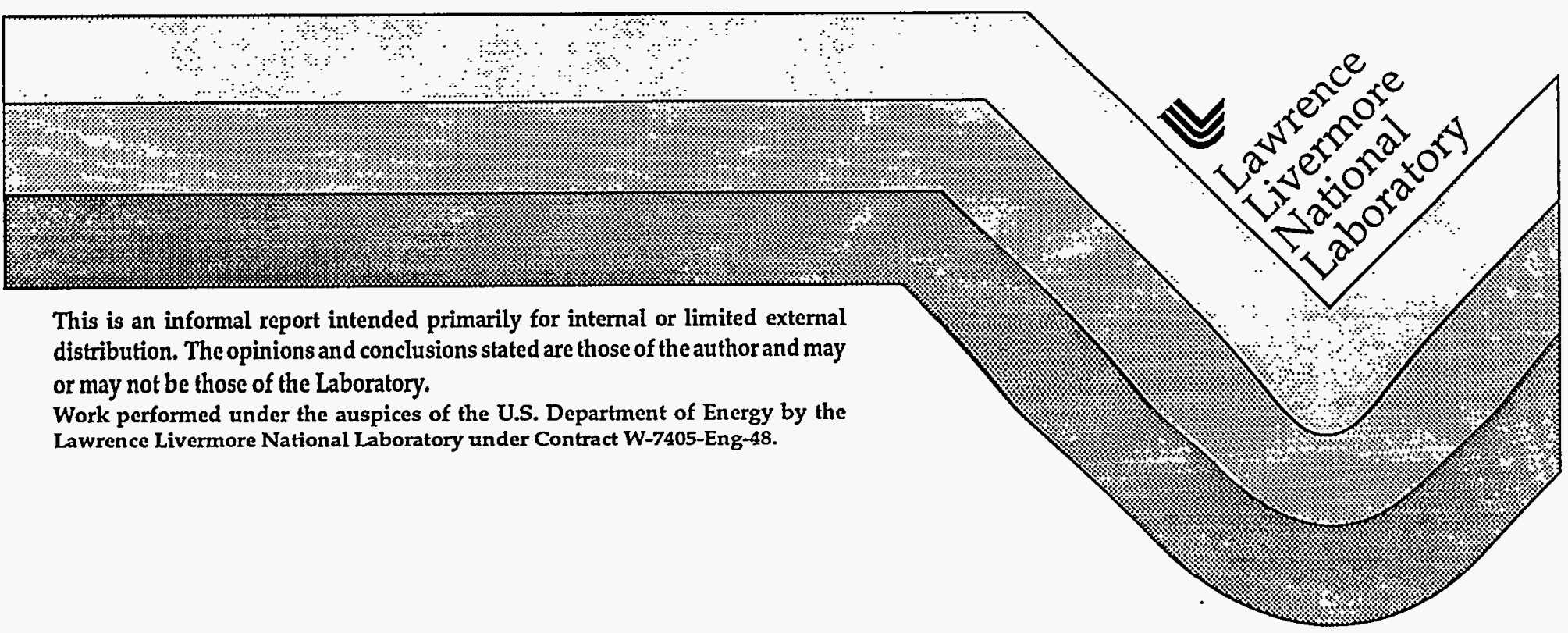




\section{DISCLAIMER}

This report was prepared as an account of work sponsored by an agency of the United States Government. Neither the United States Government nor any agency thereof, nor any of their employees, make any warranty, express or implied, or assumes any legal liability or responsibility for the accuracy, completeness, or usefulness of any information, apparatus, product, or process disclosed, or represents that its use would not infringe privately owned rights. Reference herein to any specific commercial product, process, or service by trade name, trademark, manufacturer, or otherwise does not necessarily constitute or imply its endorsement, recommendation, or favoring by the United States Government or any agency thereof. The views and opinions of authors expressed herein do not necessarily state or reflect those of the United States Government or any agency thereof. 


\section{DISCLAIMER}

Portions of this document may be illegible in electronic image products. Images are produced from the best available original document. 
Pre-shot Predictions and Instrumentation

of the KUCHEN Experiment

Bill Moran

Raymond A. Heinle

Philip E. Harben

\begin{abstract}
We calculated the peak particle velocity and peak acceleration at gage locations for the three explosions of the KUCHEN experiment. Our predictions of the peak particle velocities and accelerations are consistent with a variety of other estimates which include surface motion obtained from underground nuclear explosions in alluvium, a tamped HE explosion at the Nevada Test Site, and the ConWep estimates which are used for conventional weapons effects calculations.
\end{abstract}

We also predict the air blast over-pressure and the temperature rise in the air inside the cavity of the decoupled explosion and find that the peak pressure at the top of the cylindrical cavity is about 50 bars and that the shock-wave reverberations inside the cavity have a period of about $100 \mathrm{~ms}$. After a time on the order of $500 \mathrm{~ms}$, the shock wave reverberations inside the cavity of the decoupled explosion are considerably attenuated and the equilibrium state before any significant diffusion or thermal conduction occurs, is a pressure of 5 bars and a temperature of about $1100^{\circ} \mathrm{C}$.

The instrumentation of the experiment is designed for containment diagnostics, near-field in-situ motion, and ground motion monitoring. The containment diagnostics include an air-blast overpressure gage, an RF Interferometer, a strain gage, two thermocouples and two cavity pressure gages. Additional gages will detect the presence of hazardous detonation products. Near field motion diagnostics include four threeaxis accelerometers at various depths and a single three-axis velocity gage. The seismic ground motion sensors are located in 24 distinct locations and distributed in a modified symmetrical pattern around the borehole.

Using a simple constitutive model which correctly predicts peak particle velocity data in porous alluvium, we calculated a decoupling factor that varies from 4 to 11 in the frequency range between 1 and 30 hertz. Using that same constitutive model, we calculated a decoupling factor of 15 in a spherical cavity with equivalent volume. 


\section{Introduction}

KUCHEN is designed with a two fold purpose:

1. To carry out an experiment which exercises some aspects of a typical underground nuclear test.

2. To evaluate decoupling in high-aspect-ratio cavities by acquiring seismic information which is applicable to ongoing efforts at LLNL in the area of Comprehensive Test Ban Treaty (CTBT) monitoring and non-proliferation.

The experiment, which is scheduled to start in June 1995 at the Nevada Test Site area 9 (U9Cu), consists of two tamped and one decoupled explosion. A preliminary estimate of the seismic decoupling factor is described by Glenn (1995). Here we provide another estimate as well as velocity, pressure, and temperature estimates at the locations of various gages. Figure 1 shows a schematic diagram of the borehole, charge location and close-in instrumentation. KUCHEN is divided into three distinct phases, as described below:

\section{Phase I}

A $50 \mathrm{~kg}$ explosive charge (C4) will be placed approximately $93 \mathrm{~m}$ below the surface, close to the bottom of an existing hole which was determined to be unusable for a nuclear test. The explosive will be stemmed in place, along with instrumentation for monitoring and diagnosing the resulting detonation. An array of surface instruments, fielded jointly by Lawrence Livermore and Los Alamos National Laboratories, will be deployed on the desert surface, radiating outward from the point of detonation.

\section{Phase II}

The second explosion will be detonated in a cavity constructed by emplacing a wiper assembly in the hole at the bottom of the surface casing, approximately $36 \mathrm{~m}$ below the surface. A stemming operation will be initiated, filling the hole from the emplaced wiper to the surface, but leaving a void beneath the wiper. A simulated nuclear device delivery will occur using a second $50 \mathrm{~kg}$ explosive charge which will be emplaced through the wiper assembly to a depth of approximately 65 $\mathrm{m}$, along with similar down-hole instrumentation as described above. The decoupled explosion, will be detonated in a cylindrical cavity with a 
length-to-diameter ratio of 14.5 , and a volume $\left(158 \mathrm{~m}^{3}\right)$ equal to that which would allow near maximum decoupling if the cavity volume were spherical. The emplacement pipe will be stemmed. Remote firing system "dry runs" from the control room, a final countdown, detonation, and a re-entry will all be exercised, as directed by the Test Controller.

Phase III

A final $50 \mathrm{~kg}$ explosive charge will be emplaced at the same location as the explosion in phase II, and the void beneath the wiper will be stemmed. The third explosion will produce a seismic signature from a tamped explosion for comparison with the untamped data at the same depth. The tamped explosions from phases I and III, detonated at different depths (93 and $65 \mathrm{~m}$ below the surface) will determine local path effects. The same array of seismic instrumentation will be used. Upon completion of this last phase, the instrumentation will be collected, the surface facilities dismantled and removed, and the area around the top of the hole cleaned up, completing the KUCHEN exercise.

\section{Containment Diagnostics}

The containment diagnostics provide for monitoring of the height of the various grouted zones as they are poured. Temperature sensors will monitor the temperature of the exothermic reaction (normally not to exceed 75 degrees $\mathrm{C}$ ) in the grout as it cures. Additional transducers will measure the strain on the emplacement pipe due to the grout and stemming material, the pressure and temperature of the Phase II cavity after the explosive has been detonated, and the concentration of carbon monoxide in the stemming material and at the top of the emplacement pipe. The blast overpressure at the top of the phase II cavity will be measured.

\section{Near Field Motion}

Near field in-situ motion diagnostics will measure the motion in the inelastic regime due to the explosive source. These transducers include four three-axis accelerometers at various depths and a single three-axis velocity gage. Two of the three-axis accelerometers and the three-axis velocity gage are located at a depth of $30 \mathrm{~m}$. One of these accelerometers will have a frequency response of $200 \mathrm{~Hz}$ while the other will have a response of about $750 \mathrm{~Hz}$. See table I for a complete description of the containment diagnostics and near-field sensors. 


\section{$\underline{\text { Surface Seismic Motion Instrumentation }}$}

The layout of surface ground motion sensor stations is shown in plan view on Figure 2. There are a total of 24 distinct geographical station locations distributed around the KUCHEN borehole in a modified symmetrical pattern. Two radials separated by 90 degrees, Leg N69E and S21E, are more densely instrumented in the near-field and the farfield. Four other legs contain only one instrumented station. This sensor pattern was chosen so that ground motion characteristics as a function of bearing and distance from the shotpoint in the near and far field could be recorded with a minimum number of stations.

The location of each station is prepared to provide good coupling of the ground motion sensor to the earth. This is accomplished, as shown in Figure 3 , by auguring a shallow hole and pouring a concrete pad. A large diameter PVC tube is embedded in the concrete and the ground motion sensors are emplaced within the PVC tube on the concrete pad. A tube cap and cable feed-through complete the sensor shelter.

There are two types of surface ground motion sensors that will be used in KUCHEN experiments: Sprengnether S-6000 model seismometers and Wilcoxon model 731 accelerometers. The S-6000 seismometers are a 3axis electromagnetic open-loop seismometer package. The sensors output a voltage proportional to ground velocity. The frequency response has been tested by the manufacturer on a shaketable and is flat to velocity between $2 \mathrm{~Hz}$ and $50 \mathrm{~Hz}$. The manufacturer expects the response to remain flat up to about $300 \mathrm{~Hz}$ based on mechanical design considerations, however there is potential for parasitic resonance between 50 and $300 \mathrm{~Hz}$. Frequency response above $50 \mathrm{~Hz}$ has not been tested. Below $2 \mathrm{~Hz}$ the response falls off as $1 / \mathrm{f}$. The seismometer physical clip level is about $0.02 \mathrm{~m} / \mathrm{sec}$ at $2 \mathrm{~Hz}$. This velocity is near the estimates of peak ground velocity at the surface very close to the borehole in the fully tamped experiment, however, the expected dominant frequency at this velocity should be close to $40 \mathrm{~Hz}$. At $40 \mathrm{~Hz}$ and $0.02 \mathrm{~m} / \mathrm{sec}$ the $S-6000$ is at least a factor of 10 below clip level. Consequently, the S-6000 sensors can be emplaced at every station location.

The 731 accelerometers are 3-axis piezoelectric open-loop sensor packages. The sensor's voltage output is proportional to ground acceleration. The frequency response, according to the manufacturer's specifications, is flat to acceleration within $10 \%$ between $1.5 \mathrm{~Hz}$ and 300 
$\mathrm{Hz}$. The accelerometer is flat to acceleration within $3 \mathrm{~dB}$ between 1 and $500 \mathrm{~Hz}$.

Unfortunately, the physical clip level is $0.5 \mathrm{~g}$ which is within the estimates of peak surface ground acceleration at the close-in stations. The 731 sensors will be emplaced at the $80 \mathrm{~m}$ station locations and further out.

\section{Calculations:}

We used the two-dimensional hydro-code CALE (Tipton 1987) in all our simulations. CALE was chosen because of its automatic rezoning and slideline capabilities both of which are necessary for the decoupled calculation. The equation-of-state (EOS) for the rock included an elastic portion until the onset of pore crushing at $2.0 \mathrm{MPa}$ (20 bars), and a pore collapse portion until complete crushing at $1 \mathrm{GPa}$ $(10 \mathrm{~kb})$. Unloading was done at constant porosity at a slope which varied, smoothly with density, between that of the elastic region and that of the fully crushed material. The work-point material properties were: a density $\rho=2030 \mathrm{Kg} / \mathrm{m}^{3}$, an air-filled porosity $\Psi=16.6 \%$, and a longitudinal sound speed $\mathrm{V}_{\mathrm{p}}=1737 \mathrm{~m} / \mathrm{s}$. Although logs from nearby holes indicated some variation with depth in the sound speed, density, and air-filled porosity, we did not include any layering in these preliminary calculations. Near the surface, the material properties were estimated to be: $\rho=1700 \mathrm{Kg} / \mathrm{m}^{3}, \Psi=25.6 \%$, and $\mathrm{V}_{\mathrm{p}}=800 \mathrm{~m} / \mathrm{s}$. We used the density and air filled porosity at the work point but have chosen a weighted average sound speed of $1450 \mathrm{~m} / \mathrm{s}$, a constant yield strength of 10 bars, a constant Poisson's ratio of 0.3 , and did not include a fracture model or the effects of overburden.

The equation of state of the C4 explosive material was based on the work of Dobratz and Crawford (1985). The JWL (Lee 1968) parameters were: $\rho=1.601 \mathrm{~g} / \mathrm{cm}^{3}, \mathrm{~A}=6.0977 \mathrm{Mb}, \mathrm{B}=0.1295 \mathrm{Mb}, \mathrm{R} 1=4.5, \mathrm{R} 2=$ $1.40, \omega=0.25$ and $\mathrm{E}_{0}=0.09 \mathrm{Mb}-\mathrm{cm}^{3} / \mathrm{cm}^{3}$. The total energy, $281 \mathrm{MJ}$ (6.71E-05 kilotons of TNT), was deposited at time zero in a sphere of radius $0.195 \mathrm{~m}$ and a volume equal to that of the explosive material.

In these preliminary calculations, we did not use a tabular equation of state for the air but rather an ideal gas approximation with a constant $\gamma$ $=1.4$. The parameter $\gamma$ affects the decoupling factor as follows: In a fully decoupled explosion, it can be shown that the asymptotic value of the reduced displacement potential $\left(\phi_{\infty}\right)$ is proportional to $\gamma-1$. 
Although the initial value of $\gamma$ for air at room temperature and 1 bar is $1.4, \gamma$ drops to 1.34 at $1000^{\circ} \mathrm{C}$ and 10 bars. Thus, the difference between using a $\gamma$ of 1.34 and a $\gamma$ of 1.4 is a $15 \%$ change in $\phi_{\infty}$

We started the calculations in polar coordinates with a fine mesh and ran them until the shock front reached the edge of the hole (about 200 $\mu \mathrm{s})$. The initial zone size in the polar mesh was $2 \mathrm{~cm}$ thus allowing for 10 zones in the explosive and good energy conservation at early time. We then linked to a much coarser rectangular mesh which extended several hundred meters and in which the zone sizes increased geometrically away from the source. The geometric ratio throughout the mesh was less than $0.6 \%$ and the total number of zones in the problem was 281,400 . We used the same mesh throughout the calculations of the three phases. Figure 4 shows a portion of the mesh extending to $160 \mathrm{~m}$ below the surface. The right side of the figure shows the calculated pressure contours at $50 \mathrm{~ms}$ for the decoupled explosion.

\section{Phase I (Tamped):}

Figures 5 and 6 show the calculated axial and radial velocities at 4 seismic gage locations during the first $200 \mathrm{~ms}$. The peak axial velocity is in the downward direction, a result which is sensitive to the constitutive model of the rock but is consistent with the measurements from shot 24 of the OSSY (Swift 1991) HE tamped shot. A large peak velocity in the downward direction is consistent with an initially steep unloading. We have chosen shot 24 for comparison because of its similarity to KUCHEN. It was detonated at comparable depth $(111 \mathrm{~m})$ in similar rock (alluvium), and had approximately the same amount of explosive (45.5 $\mathrm{kg}$ of $\mathrm{C} 4$ ). In table II we compare our predicted peak upward and downward surface velocity with measurements from shot 24 at 20,40, and $80 \mathrm{~m}$ away from the borehole. The OSSY results have been corrected to account for the different yield and depth of burial assuming that the peak velocity decays inversely with distance and scales linearly with yield. Although these assumptions are strictly correct in an elastic medium for a point source, they are approximately correct in this case because the comparison is made far away from the inelastic region and the largest correction factor is only about 1.3. In the last column of table II we also include velocity estimates from contained underground nuclear explosions in alluvium (Bass 1992). There are no estimates for the downward peak velocity from the nuclear data and no measurements from OSSY shot 24 at $140 \mathrm{~m}$ away from the borehole. 
Table II shows that the calculated peak surface velocities are consistent with the OSSY 24 experiment as well as the estimates from Nuclear data. In Table III we compare the calculated peak accelerations of the first motion with those from OSSY 24. There were no acceleration data at that range from nuclear explosions in alluvium.

The calculated peak accelerations are comparable to those estimated from OSSY 24. Near the borehole, the values are larger than $0.5 \mathrm{~g}$ which is the physical clip limit for the Wilcoxon model 731 accelerometers. The calculated peak velocity in the radial direction increases with distance from the borehole and reaches its maximum at the third gage $(80 \mathrm{~m})$, then decreases gradually. The reason for the initial increase with distance is purely geometrical: The component of the velocity in the radial direction must vanish on axis at the borehole.

Figures 7 and 8 show the calculated axial and radial velocities at 2 containment gage locations: stations 21 and 61 . The small signal at station 21 around $120 \mathrm{~ms}$ is a result of the reflection from the surface. The time of arrival of that signal is a measure of the average sound speed between the surface and the gage. The experimental time of arrival of that reflection will provide a consistency check on a model for the geological layering at the U9cu hole.

Phase II (Decoupled):

Figures 9 and 10 show the calculated axial and radial velocities at 4 seismic gage locations during the first $200 \mathrm{~ms}$. Compared to the signals from the tamped explosion of phase I, these signals show a lot of structure due to the reverberations inside the cavity. The dominant frequency in these signals is on the order of 200 hertz and we expect our gages to adequately record most of the structure.

Figures 11 and 12 show the calculated axial and radial velocities at 3 containment gage locations during the first $150 \mathrm{~ms}$. The calculation predicts that station 21 which is only $1 \mathrm{~m}$ below the bottom of the cavity, will experience the highest peak velocity $(1.1 \mathrm{~m} / \mathrm{s})$ and highest peak acceleration ( $130 \mathrm{~g}$ ) during this phase of the experiment. The decoupled configuration creates large stagnation pressures at the bottom and top of the cavity and these pressures generate a strong shock which propagates into the rock.

Stations 22 will be added during this phase of the experiment and will be located $6 \mathrm{~m}$ above the top of the cavity. Here again, the large 
stagnation pressure at the top of the cavity will cause a large signal at this station. The calculation predicts a peak velocity of $0.08 \mathrm{~m} / \mathrm{s}$ and a peak acceleration of $8 \mathrm{~g}$. Station 23 will be added at that same location but with different gage settings in order to provide some redundancy.

The predictions in this phase cannot easily be compared with the estimates from Bass (1992) or the ConWep (Hyde 1992) code because both of these estimates are based on tamped explosions.

Figure 13 shows the calculated blast pressure, $30 \mathrm{~cm}$ below the top of the cylindrical cavity, during the first $300 \mathrm{~ms}$. The dashed line was generated from a calculation which modeled all the rock around the cavity. The solid line was from a calculation in which only $1 \mathrm{~m}$ of rock around the cavity was modeled. The good agreement between the two calculations indicates the adequacy of the zoning in our simulations. It also confirms that although the pressure inside the cavity affects the response of the rock, the motion of the rock is small and has a negligible effect on the pressure inside the cavity. The calculated pressure in figure 13 consists of a series of rapidly attenuating pulses with a period of about $100 \mathrm{~ms}$. These pulses correspond to the shock wave reverberations and reflections from the top and bottom of the cavity.

The equilibrium pressure inside the cavity was estimated to be $0.55 \pm 0.05 \mathrm{MPa}(5.5 \pm 0.5$ bars). To estimate the temperature inside the cavity before any significant diffusion or thermal conduction takes place, we assume that the air and explosive products inside the cavity may be treated as an ideal gas and that the explosive products have a molecular weight comparable to that of air. Both of these assumptions are reasonable because the final pressure is only 0.55 $\mathrm{MPa}$ implying a nearly ideal behavior, and the explosive products namely water vapor, carbon monoxide, carbon dioxide, and various nitrogen oxides have a molecular weight of $28 \mathrm{~g} / \mathrm{mole}$ compared with $29 \mathrm{~g} / \mathrm{mole}$ for air. From the ideal gas approximation, the pressure is equal to the product of the mass density, the universal gas constant $\left(R=8.314 \mathrm{~J} \mathrm{OK}^{-1} \mathrm{~mole}^{-1}\right)$, and the temperature in Kelvin.

Since the mass of the air inside the cavity is $169 \mathrm{~kg}$, and the mass of the explosive is $50 \mathrm{~kg}$, we calculate a final density of $1.386 \mathrm{Kg} / \mathrm{m}^{3}$, an average molecular weight of $28.8 \mathrm{~g} / \mathrm{mole}$, and a final temperature of

\footnotetext{
* The KUCHEN experiment will be conducted at 6 am at an altitude of about 4000 feet $(1219 \mathrm{~m})$. At that height, the density of air is 0.87 of its value at sea level. Assuming a temperature of $15^{\circ} \mathrm{C}$, the density of the air in the cavity is 1.07 $\mathrm{Kg} / \mathrm{m}^{3}$.
} 
$1375{ }^{\circ} \mathrm{K}$, or $1102{ }^{\circ} \mathrm{C}$. The estimated high temperature inside the cavity suggests that the transmitting cable from the accelerometer at station 21 is unlikely to survive beyond phase II unless it is very well thermally insulated.

Phase III (Tamped):

Figures 14 and 15 show the calculated axial and radial velocities at the same 4 seismic gage locations during the first $200 \mathrm{~ms}$. As expected, these velocity traces are very similar to but somewhat higher than those in phase $\mathrm{I}$.

Figures 16 and 17 show the calculated axial and radial velocities at 3 containment gage locations during the first $150 \mathrm{~ms}$. Because of the high temperature that is expected inside the cavity of phase II, signals from station 21 may not be recorded.

\section{Decoupling factor}

In Figure 18 we plot the calculated normalized reduced velocity potential (RVP) as a function of frequency for the decoupled (phase II) and tamped (phase III) explosions. The RVP was calculated at the furthest point for which the velocity time-history was unaffected by the boundary of the mesh. This point corresponds to a location on the surface $230 \mathrm{~m}$ away from the borehole and $239 \mathrm{~m}$ from the explosive, or a distance equal to 7 times the length of the cylindrical cavity and 3.7 times the burial depth of the explosive. Our analysis of the velocity time-history at several locations on the surface indicates that the location at which we calculated the RVP is not far enough away to be considered in the far field and that the increase in RVP at low frequency is a likely consequence of the proximity to the source. Nevertheless, we found that the decoupling factor has nearly converged at the location we considered.

The decoupling factor (defined here as the ratio of the RVP for the tamped explosion divided by the RVP for the decoupled explosion) varies from 4 to 11 in the frequency range between 1 and 30 hertz. We would like to emphasize however that our 1 dimensional calculations indicated that the asymptotic value of the reduced displacement potential $\left(\phi_{\infty}\right)$, and hence the decoupling factor, is very sensitive to the details of the constitutive model of the rock (alluvium) and that reasonable variations in the crush onset, yield strength, and crush curve of the rock can change $\phi_{\infty}$ by as much as a factor of two or more. We 
estimated a corner frequency from the intersection of two straight lines that best fit the spectrum in the ranges from 1 to 10 hertz and from 100 to 300 hertz. We found that the corner frequency for the tamped explosion is about 40 hertz, a result which is consistent with the measurements of the OSSY 24 experiment. For the decoupled explosion, we calculated a corner frequency of 80 hertz.

In this preliminary report, we did not calculate the decoupling factor at the stations located 640 and $1280 \mathrm{~m}$ away from the borehole because direct simulations with a hydrocode are prohibitive ${ }^{*}$. We describe however how these calculations can be made and we intend to make such calculations after we validate our rock constitutive model. The approach to use is that of Glenn et al (1985) which consists of using the hydrocode to compute the displacement and tractions on an elastic surface near the cavity, then invoking the integral representation theorem to calculate the displacement field anywhere in the region outside the elastic surface. Alternatively, a semi-analytical approach is to compute the time history of the pressure at several locations on the cavity wall. Then apply that pressure to the inside surface of spherical cavities and use the superposition principle to calculate the combined far field displacement.

To estimate the effect of the cavity aspect ratio on the decoupling factor, we calculated a decoupled explosion in a spherical cavity with equivalent volume. The decoupling factor at low frequency was 15 . We thus find a degradation of the decoupling factor from 15 for an aspect ratio of 1 , to a value ranging from 4 to 11 in the frequency between 1 and 30 hertz for an aspect ratio of 14.5. This result, although preliminary, is consistent with the calculations of Glenn and Rial (1987) who found that for a nuclear explosion in salt, the decoupling factor was degraded by less than a factor of 2 for aspect ratios ranging from 10 to 20. Our results also complement the calculations of Stevens et al (1991) who used an ellipsoidal geometry with an aspect ratio of 4 and found little difference in the decoupling factor when compared with a spherical geometry. Recent experiments in limestone, reported by Reinke et al (1995), have also suggested that for cavities with aspect ratios less than 4 there is little degradation in the decoupling factor. Measurements from the KUCHEN experiment as well as other

\footnotetext{
* Each of the 3 simulations that we carried out required about 1 week of computer time on an IBM risk 6000 model 580 workstation. We estimated that direct hydrocode calculations of the RVP at the station located $1280 \mathrm{~m}$ away from the borehole would require 6 months of computer time.
} 
calculations and/or experiments would further quantify the effect of the cavity aspect ratio and rock properties on the decoupling factor.

\section{Summary and conclusions}

We have estimated the peak particle velocity and peak acceleration at various gage locations for the KUCHEN experiment. Our calculations combined with data from an HE shot in alluvium have led to the decision to substitute Sprengnether model S-6000 seismometers instead of accelerometers in the region close to the borehole. This choice, which comes at the expense of a somewhat lower resolution at higher frequencies, eliminates any risk of physical gage:clip.

We find that the temperature inside the cylindrical cavity of the decoupled explosion will reach about $1100^{\circ} \mathrm{C}$, a value high enough to damage the transmitting cable from one of the accelerometer stations below the cavity. It is thus unlikely that acceleration data will be obtained from station 21 during phase III of the experiment.

The calculated decoupling factor is very sensitive to the details of the constitutive model of the rock. Using a simple constitutive model which correctly predicts peak particle velocity data in porous alluvium, we calculated a preliminary decoupling factor that varies from 4 to 11 in the frequency range between 1 and 30 hertz. For comparison, we calculated a decoupling factor of 15 in a spherical cavity with equivalent volume. This low decoupling factor is due to the high initial porosity of the alluvium. In a configuration similar to that of KUCHEN but with non-porous material, the decoupling factor would be much higher.

\section{Acknowledgments:}

The authors would like to acknowledge the various discussions with Norm Burkhard, Lew Glenn, and John Rambo. Pat Lewis provided the drawings of the layout of surface ground motion monitoring stations (figure 2) and the site preparation drawing (figure 3 ). 


\section{References}

Bass, R. C., "Summary of vertical surface motion data obtained from contained detonations in alluvium, tuff, granite, salt, andesite, rhyolite, and dolomite," private communication, September 1992.

Dobratz, B. M., and P. C. Crawford, "LLNL Explosives Handbook," Lawrence Livermore Laboratory report UCRL-52997, January 1985.

Glenn, L. A., A. J. C. Ladd, B. Moran, and K. A. Wilson "Elastic radiation from explosively loaded ellipsoidal cavities in an unbounded medium," Geophys. J. R. astr. Soc. (1985) 81, 231-241.

Glenn, L. A. and J. A. Rial. "Blast wave effects on decoupling with axisymmetric cavities," Geophys. J. R. astr. Soc., 91.229 (1987).

Glenn, L. A. "KUCHEN: An Experiment to Evaluate Decoupling in HighAspect-Ratio Cavities", UCRL-JC-119103, January 1995.

Hyde, D. W., "ConWep: Conventional Weapons Effects," A code based on TM 5-855-1 and SL-88-1, reports available from US Army Engineer Waterways Experiment Station 3909 Halls Ferry Road, Vicksburg, MS 39180.

Lee, E. L., H. C. Hornig, and J. W. Kury, "Adiabatic Expansion of High Explosive Detonation Products," report UCRL-50422, Lawrence Radiation Laboratory, Livermore, CA, May 2, 1968.

Reinke, R., A. Leverette, A. Martinez, D. Murrell, and C. Joachim, "High explosive decoupling experiments in hard rock; the Magdalena tests, DNA/ACDA VERITECH II Symposium, Washington, D.C., January 1995.

Stevens, J. L., N. Rimer, J. R. Murphy, T. G. Barker, E. Bailey, E. J. Halda, W. J. Proffer, S. H. Rogers, and B. Shkoller, "Simulation of seismic signals from partially coupled nuclear explosions in spherical and ellipsoidal cavities," Scubed Report No. SSS-FR-91-12735 (1995). Scubed Division of Maxwell Corp., P. O. Box 1620, La Jolla, CA 920381620.

Swift, R. P. "Ground Motion Analyses: OSSY (A High Explosive Experiment) and MERLIN (A Nuclear Event)," Lawrence Livermore National Laboratory Report UCRL-ID-108616, October 1991. 
Tipton, R. E., "A 2D Lagrange MHD Code," Proceedings of the Fourth International Conference on Megagaus Magnetic Field Generation and Related Topics, C. M. Fowler, R. S. Caird, and D. J. Erickson, eds., (Plenum Press, New York, 1987) pp. 299.

\section{Distribution}

LLNL

Norm Burkhard L-221

Marv Denny L-205

Don Ecker L-777

Lew Glenn L-200

Peter Goldstein L-205

Don Hamma L-142

W. J. Hannon L-205

Phil Harben L-208

Steve Hunter L-208

Steve Jarpe L-205

Glenn Mara L-49

Howard Patton L-205

Jim Reed L-777

Don Rock L-208

Terry Rossow L-154

Bernie Roth L-113

Ted Valk L-154

Carol Velsko L-231

Jim Wobser L-35

Jay Zucca L-205
EG\&G

Bill Bellow EG\&G/LVO A13-20

Terry Brown · EG\&G/AVO

Lee Davies EG\&G/LVO A13-20

Al Moeller . EG\&G/LVO A13-20

Ted Stubbs $\quad$ EG\&G/AVO 


\section{Table I: Containment diagnostics and near-field sensors}

\begin{tabular}{|c|c|c|c|c|c|c|c|}
\hline Meas Type & $\begin{array}{l}\text { Station } \\
\text { number }\end{array}$ & $\begin{array}{c}\text { Elevation } \\
\mathrm{m}\end{array}$ & \begin{tabular}{|c|} 
Radial Pos. \\
$\mathrm{m}$
\end{tabular} & Recording & 1 & $\begin{array}{c}\text { has } \\
2\end{array}$ & 3 \\
\hline 3 Axis Accelerometer & 21 av,th & 71 & 0.9 & MEAS & $x$ & $\overline{\# \#}$ & 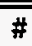 \\
\hline 3 Axis Acc/velocity & 22 uv, av, th & 30 & 0.9 & MERS & & $x$ & $x$ \\
\hline 3 Axis Accelerometer & 23 av, th & 30 & 0.9 & MERS & & $x$ & $x$ \\
\hline 3 Axis Accelerometer & 61 av & $.9 \mathrm{~m}$ deep, $15 \mathrm{~m}$ from $\mathrm{SGZ}$ & 15 & MEAS & $x$ & $x$ & $x$ \\
\hline RF Interferometer & 91 IF & To top of HE & 0 & DSP & & & $x$ \\
\hline Gas Pressure" & $33 \mathrm{PX}$ & 37 & 0.9 & SMDS & & $x$ & \\
\hline Gas Pressure* & $32 \mathrm{PX}$ & 37 & 0.9 & SMDS & & $x$ & \\
\hline Thermocouple & $33 \mathrm{TR}$ & 37 & 0.9 & - SMDS & & $x$ & $x$ \\
\hline Thermocouple & 32 TR & 37 & 0.9 & SMDS & & $x$ & $x$ \\
\hline Reflected Overpressure & $31 \mathrm{PR}$ & 37 & 0.9 & MERS & & $x$ & \\
\hline Strain gage & $84 \mathrm{SG}$ & 0 & 0 & SMDS & & $x$ & $x$ \\
\hline Conductivity probe & 81E CP & 70 & & SMDS & $x$ & & \\
\hline Temperature probe & 81E TR & 70 & & SMDS & $x$ & & \\
\hline Conductivity probe & $81 \mathrm{CP}$ & 71 & & SMDS & $x$ & & \\
\hline Temperature probe & 81D TR & 71 & & SMDS & $x$ & & \\
\hline Conductivity probe & $81 \mathrm{C} \mathrm{CP}$ & 91 & & SMDS & $x$ & & \\
\hline Temperature probe & $81 \mathrm{CTR}$ & 91 & & SMDS & $x$ & & \\
\hline Conductivity probe & $81 B \mathrm{CP}$ & 94 & & SMDS & $x$ & & \\
\hline Temperature probe & 81B TR & 94 & & SMDS & $x$ & & \\
\hline Conductivity probe & $81 A C P$ & 96 & & SMDS & $x$ & & \\
\hline Temperature probe & 81A TR & 96 & & SMDS & $\mathrm{x}$ & & \\
\hline Conductivity probe & $82 \mathrm{D} \mathrm{CP}$ & 37 & & SMDS & & & $x$ \\
\hline Temperature probe & 82D TA & 37 & & SMDS & & & $x$ \\
\hline Conductivity probe & $82 \mathrm{C} \mathrm{CP}$ & 53 & & SMDS & & & $x$ \\
\hline Temperature probe & $82 C$ TR & 53 & & SMDS & & & $x$ \\
\hline Conductivity probe & $82 \mathrm{~B} \mathrm{CP}$ & 61 & & SMDS & & & $x$ \\
\hline Temperature probe & $82 \mathrm{~B}$ TR & 61 & & SMDS & & & $x$ \\
\hline Conductivity probe & $82 \mathrm{~A} \mathrm{CP}$ & 69 & & SMDS & & & $x$ \\
\hline Temperature probe & 82A TR & 69 & & SMDS & & & $x$ \\
\hline Conductivity probe & 83D CP & 24 & & SMDS & & $x$ & \\
\hline Temperature probe & 83D TR & 24 & & SMDS & & $x$ & $x$ \\
\hline Conductivity probe & $83 \mathrm{C} \mathrm{CP}$ & 25 & & SMIDS & & $x$ & \\
\hline Temperature probe & $83 \mathrm{CTR}$ & 25 & & SMDS & & $x$ & $x$ \\
\hline Conductivity probe & $83 \mathrm{~B} \mathrm{CP}$ & 31 & & SMDS & & $x$ & \\
\hline Temperature probe & 83B TR & 31 & & SMDS & & $x$ & $x$ \\
\hline Conductivity probe & $83 A C P$ & 35 & & SMDS & & $x$ & \\
\hline Temperature probe & 83A TR & 35 & & SMIDS & & $x$ & $x$ \\
\hline Carbon Monoxide Det. & $34 C O D$ & 24 & 1 & SMDS & & $x$ & $x$ \\
\hline Explosive Gas Detector & 35EGD & 1 & 0 & SMDS & & $x$ & \\
\hline
\end{tabular}

- Transducers above wiper--Wiper is penetrated by steel tube

\# Survival beyond Stage II is doubtful 
Table II: Estimates for Phase I KUCHEN of peak upward and downward surface velocities (in $\mathrm{m} / \mathrm{s}$ ) at several locations on the surface.

\begin{tabular}{|l|l|l|l|}
\hline $\begin{array}{l}\text { Distance from } \\
\text { borehole and } \\
\text { direction of motion }\end{array}$ & $\begin{array}{l}\text { Corrected peak } \\
\text { surface velocity } \\
\text { from OSSY 24 }\end{array}$ & $\begin{array}{l}\text { Calculated peak } \\
\text { surface velocity for } \\
\text { KUCHEN Phase I }\end{array}$ & $\begin{array}{l}\text { Estimate } \\
\text { from Bass's } \\
\text { Nuclear Data }\end{array}$ \\
\hline $20 \mathrm{~m}$ (Upward) & 0.020 & 0.018 & 0.026 \\
\hline $20 \mathrm{~m}$ (Downward) & 0.032 & 0.032 & \\
\hline $40 \mathrm{~m}$ (Upward) & 0.019 & 0.017 & 0.024 \\
\hline $40 \mathrm{~m}$ (Downward) & 0.029 & 0.028 & \\
\hline $80 \mathrm{~m}$ (Upward) & 0.012 & 0.012 & 0.015 \\
\hline $80 \mathrm{~m}$ (Downward) & 0.022 & 0.020 & \\
\hline $140 \mathrm{~m}$ (Upward) & & 0.006 & 0.008 \\
\hline $140 \mathrm{~m}$ (Downward) & & 0.011 & \\
\hline
\end{tabular}

Table III: Estimates for Phase I KUCHEN of peak surface axial acceleration of the first motion (in units of $\mathrm{g}$ ) at several locations on the surface.

\begin{tabular}{|l|l|l|}
\hline $\begin{array}{l}\text { Distance from } \\
\text { borehole }\end{array}$ & $\begin{array}{l}\text { Corrected peak } \\
\text { surface acceleration } \\
\text { from OSSY 24 }\end{array}$ & $\begin{array}{l}\text { Calculated peak } \\
\text { surface acceleration } \\
\text { for KUCHEN Phase I }\end{array}$ \\
\hline $20 \mathrm{~m}$ & 0.79 & 1.1 \\
\hline $40 \mathrm{~m}$ & 0.75 & 0.98 \\
\hline $80 \mathrm{~m}$ & 0.52 & 0.49 \\
\hline $140 \mathrm{~m}$ & & 0.18 \\
\hline
\end{tabular}




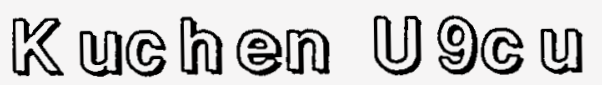

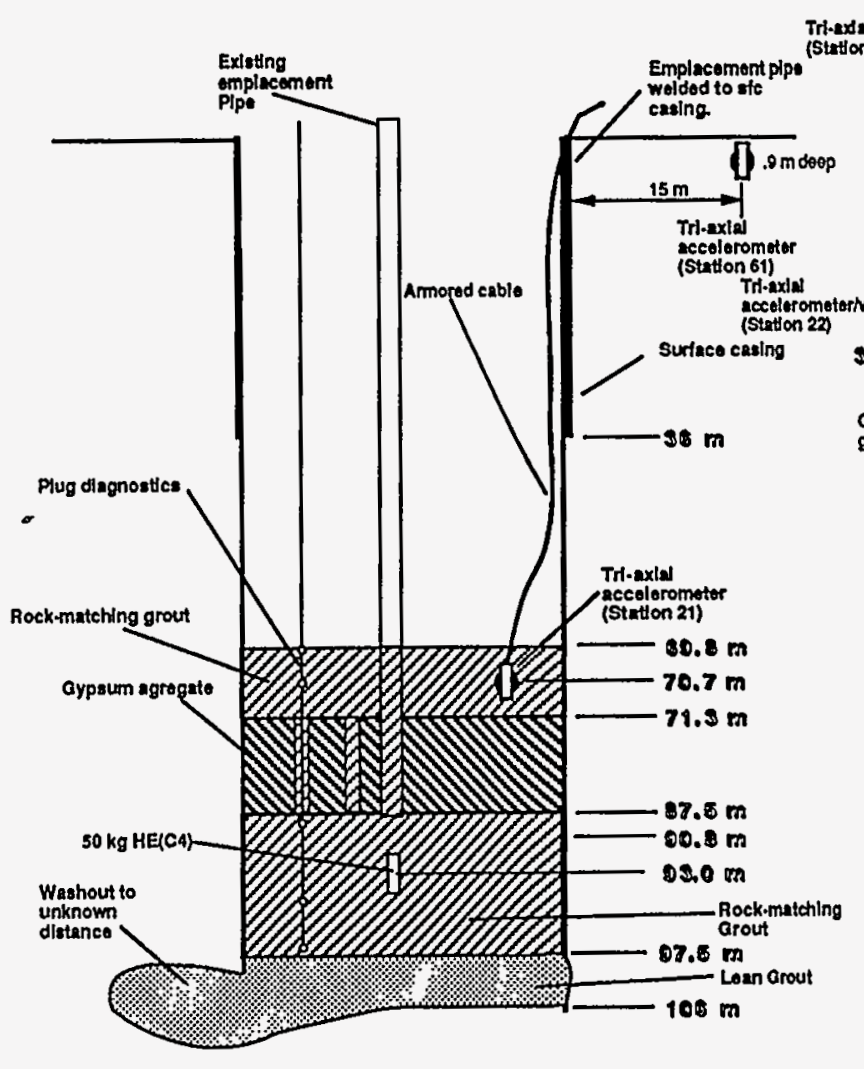

First Coupled Explosion Phase I Decoupled Explosion
Phase II

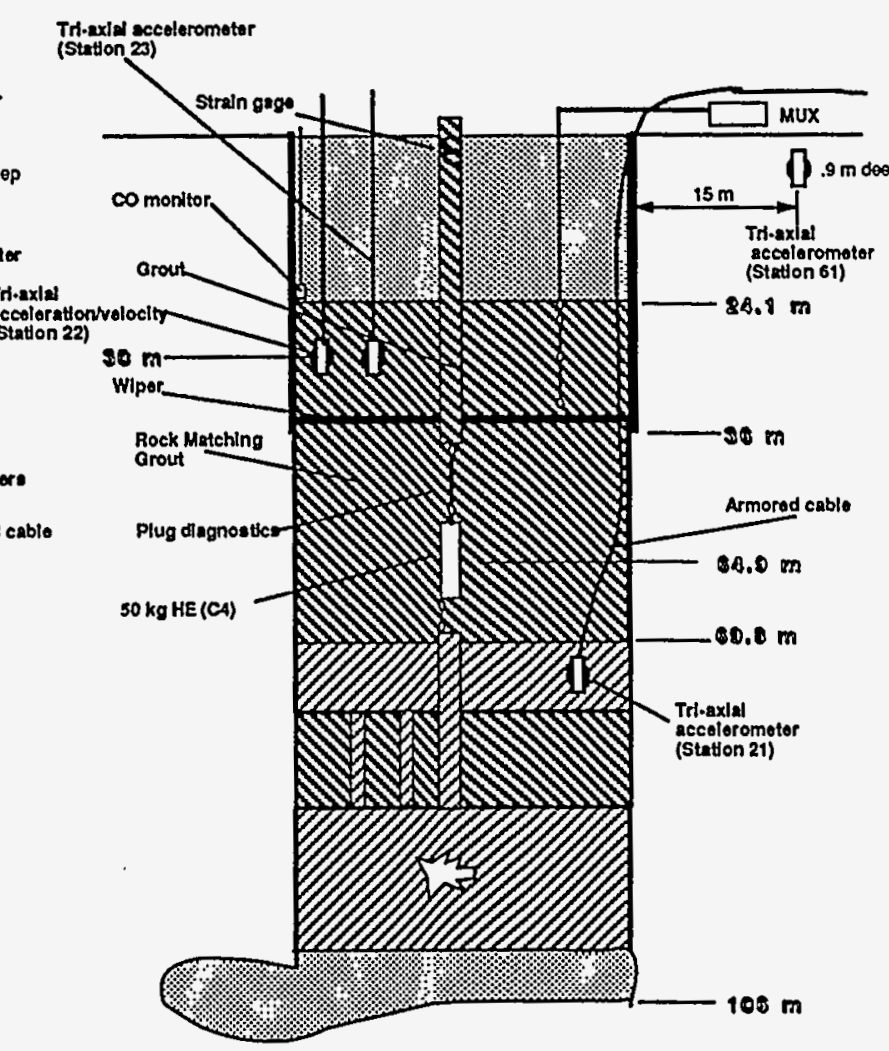

Final Coupled Explosion Phase III

Fig 1: Schematic diagram of the borehole, charge location, and closein instrumentation for the 3 phases of the KUCHEN experiment. The diameter of the borehole $(2.44 \mathrm{~m})$ has been highly expanded for clarity. 


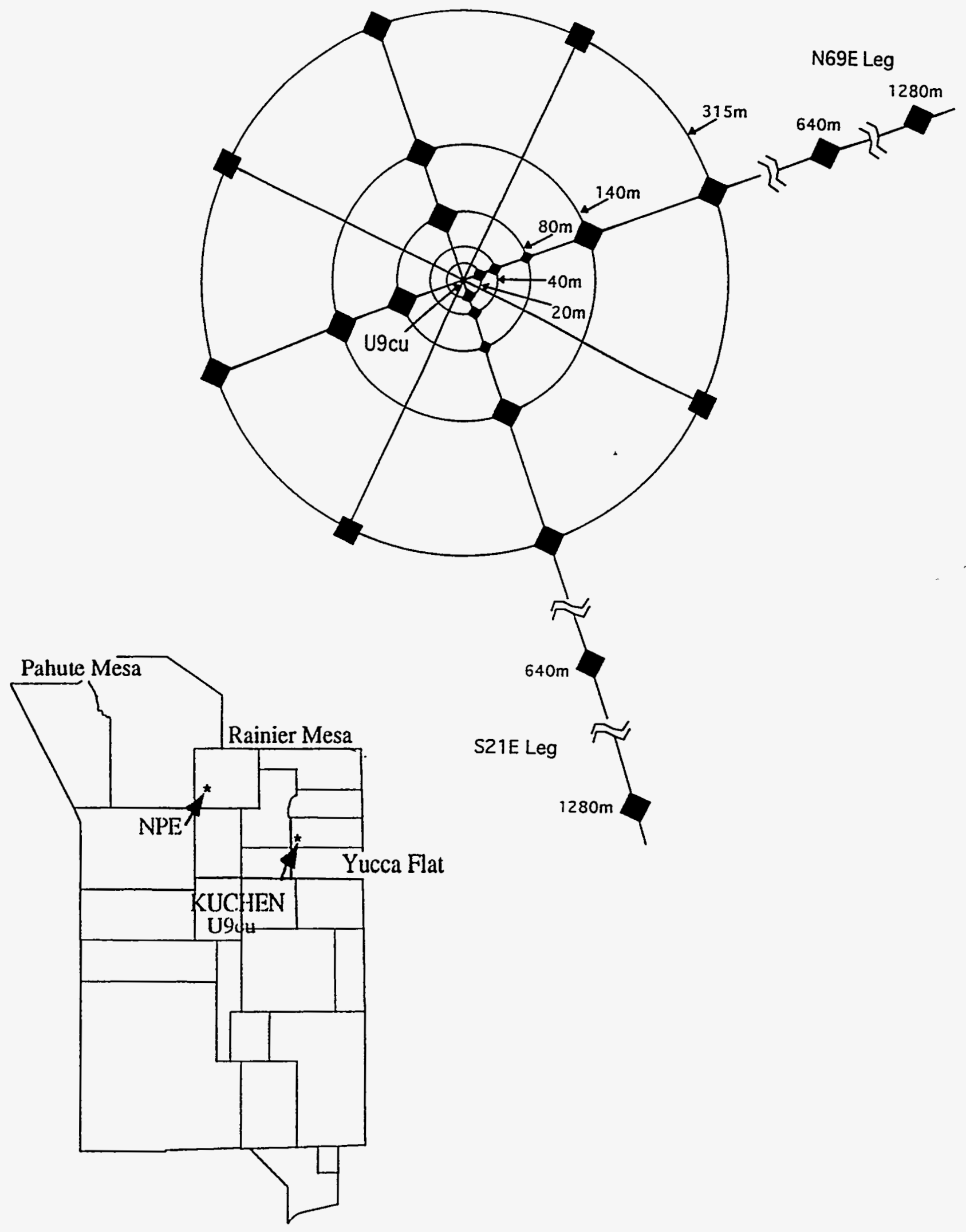

Fig 2: Layout of surface ground motion monitoring stations for the KUCHEN experiment series 


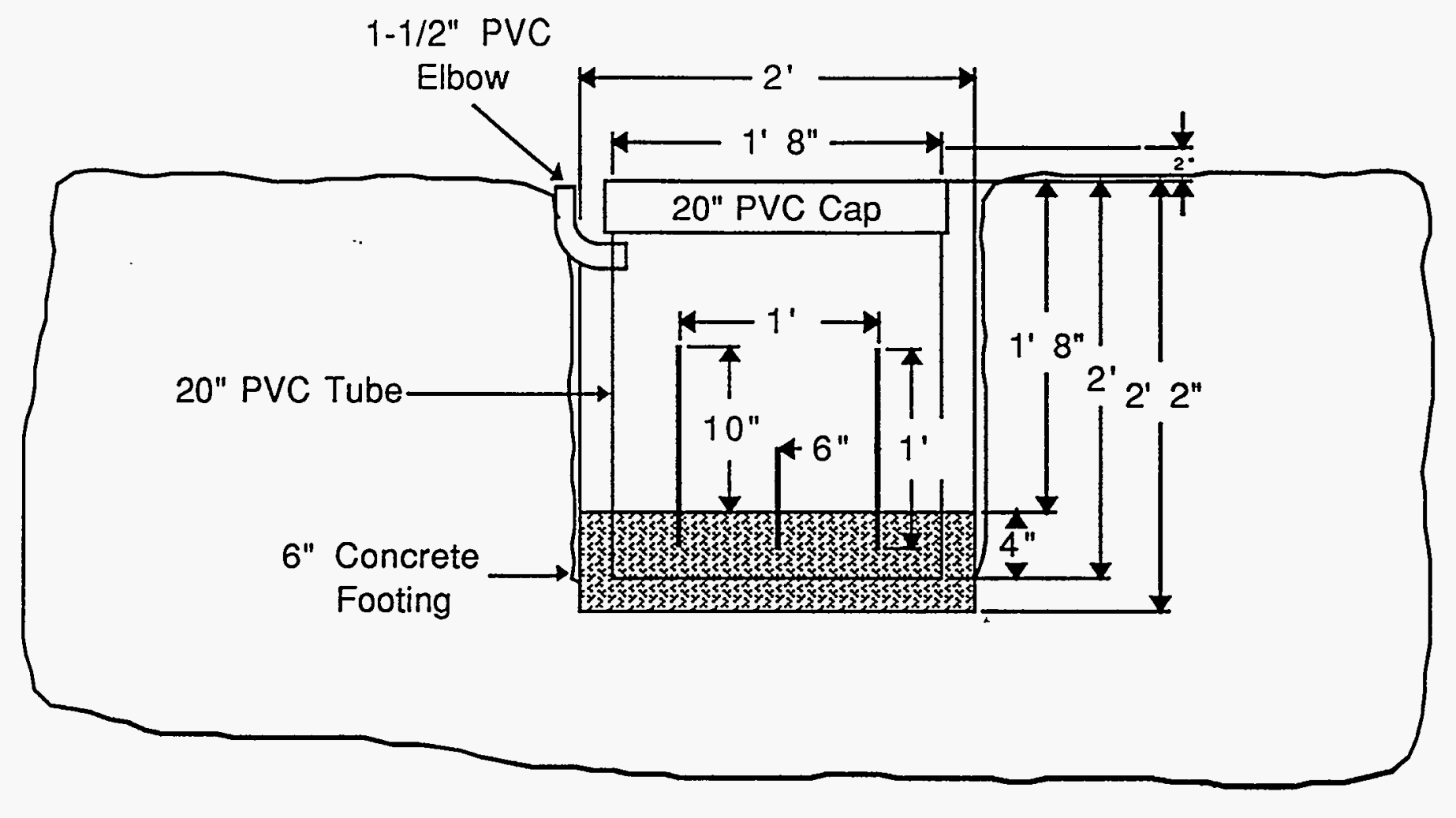

Sink Rod into Concrete 2"

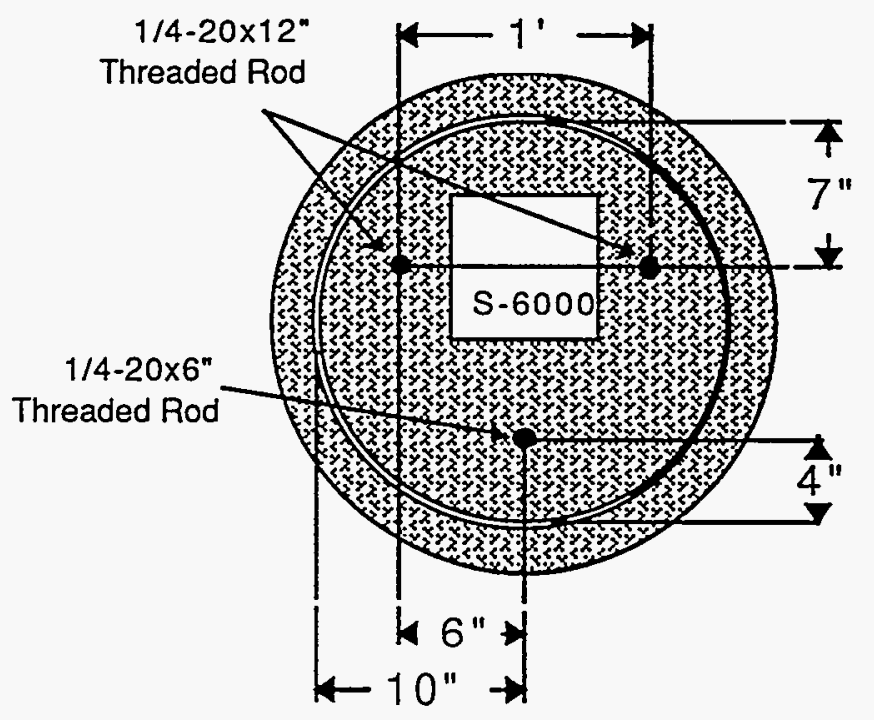

Figure 3 - Site preparation for the ground motion monitoring stations 

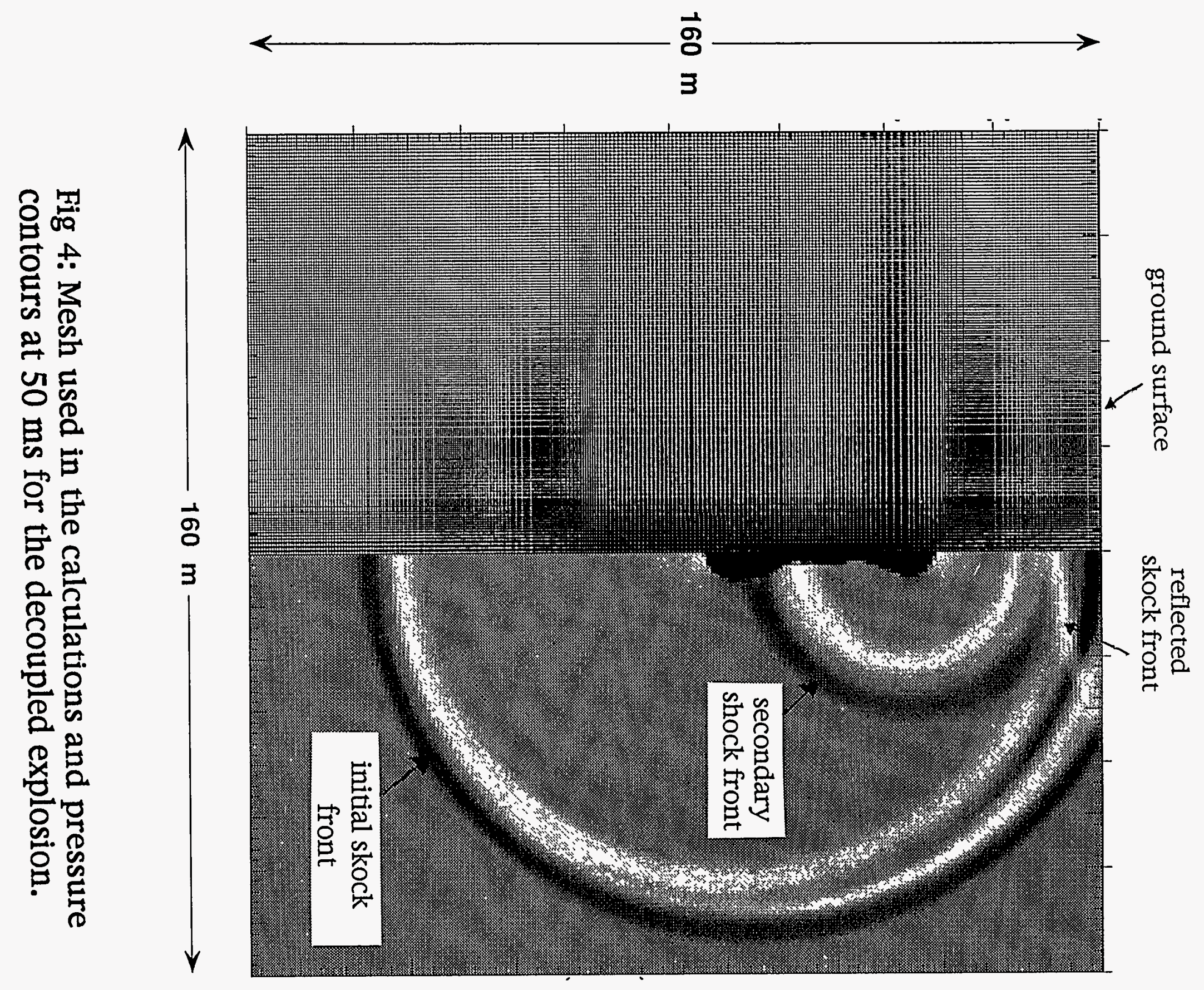

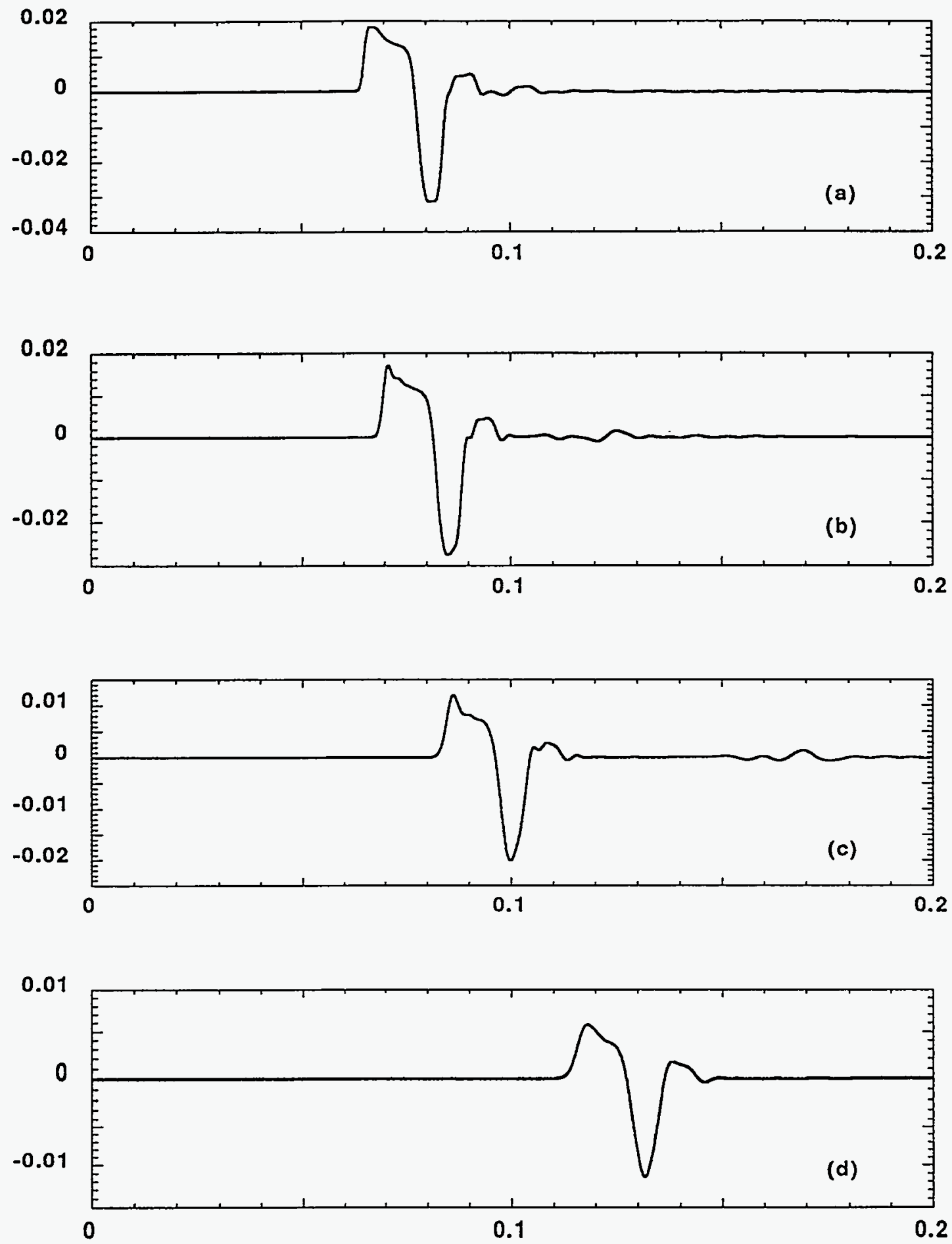

Fig 5: Calculated phase I axial velocities in $\mathrm{m} / \mathrm{s}$ versus time in seconds at 4 seismic gage locations on the surface. The distance from the gages to the drill hole is $20 \mathrm{~m}$ for a, $40 \mathrm{~m}$ for $\mathrm{b}, 80 \mathrm{~m}$ for $\mathrm{c}$, and $140 \mathrm{~m}$ for $\mathrm{d}$. 

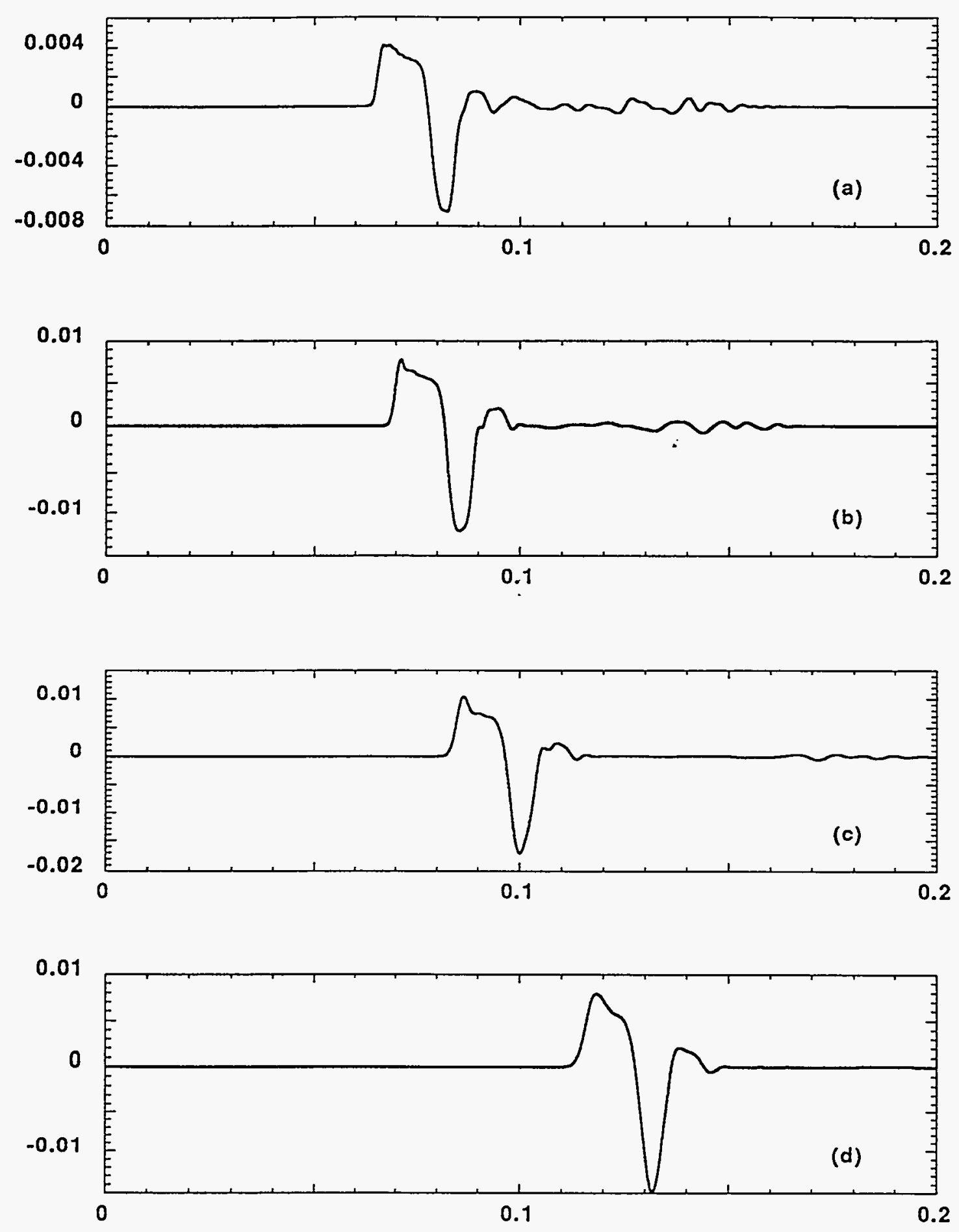

Fig 6: Calculated phase I radial velocities in $\mathrm{m} / \mathrm{s}$ versus time in seconds at 4 seismic gage locations on the surface. The distance from the gages to the drill hole is $20 \mathrm{~m}$ for a, $40 \mathrm{~m}$ for $\mathrm{b}, 80 \mathrm{~m}$ for $\mathrm{c}$, and $140 \mathrm{~m}$ for $\mathrm{d}$. 

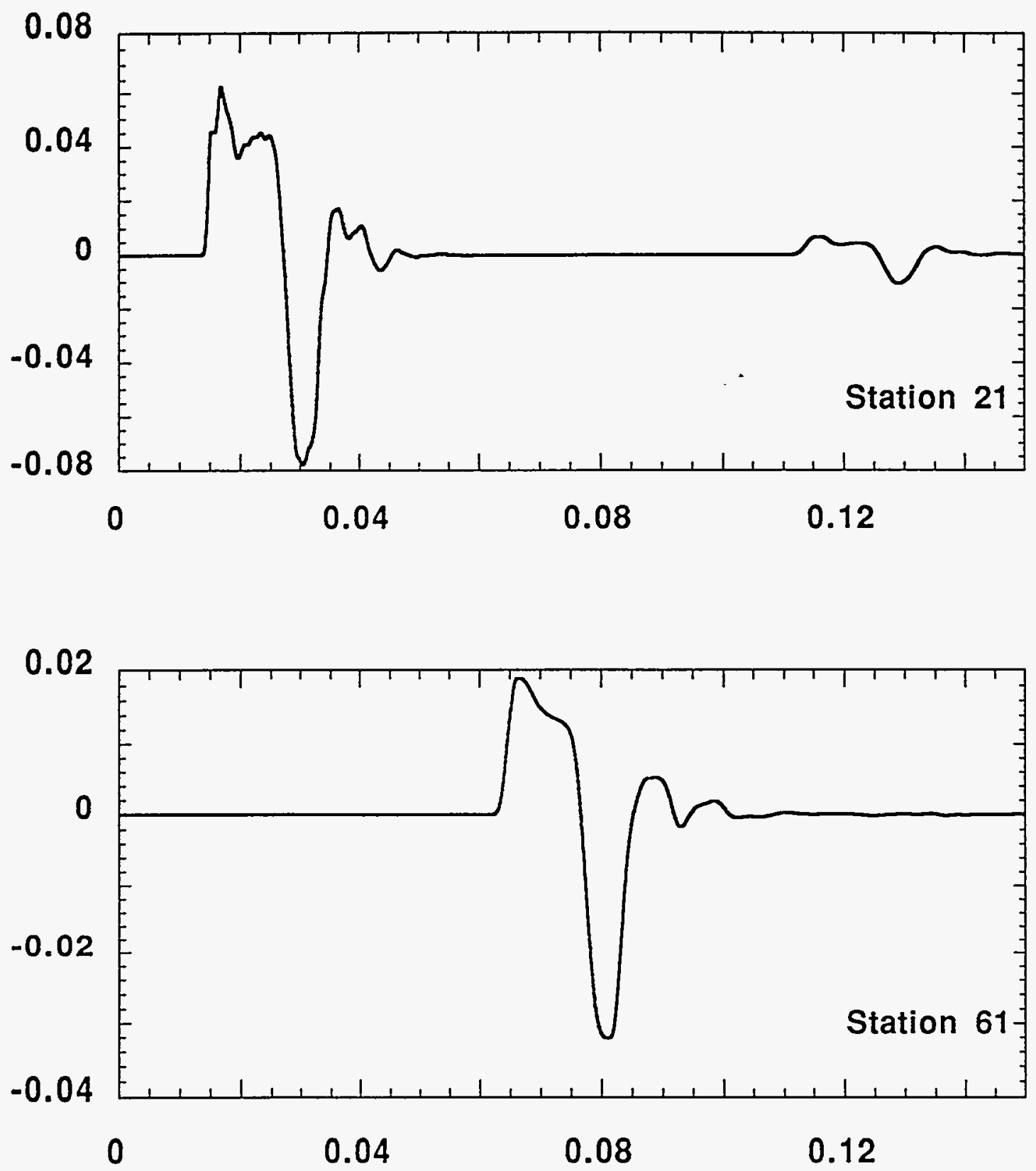

Fig 7: Calculated phase I axial velocities in $\mathrm{m} / \mathrm{s}$ versus time in seconds at 2 containment gage locations. Station 21 is $71 \mathrm{~m}$ downhole and station 61 is $15 \mathrm{~m}$ away from the borehole and $0.9 \mathrm{~m}$ below the surface. 

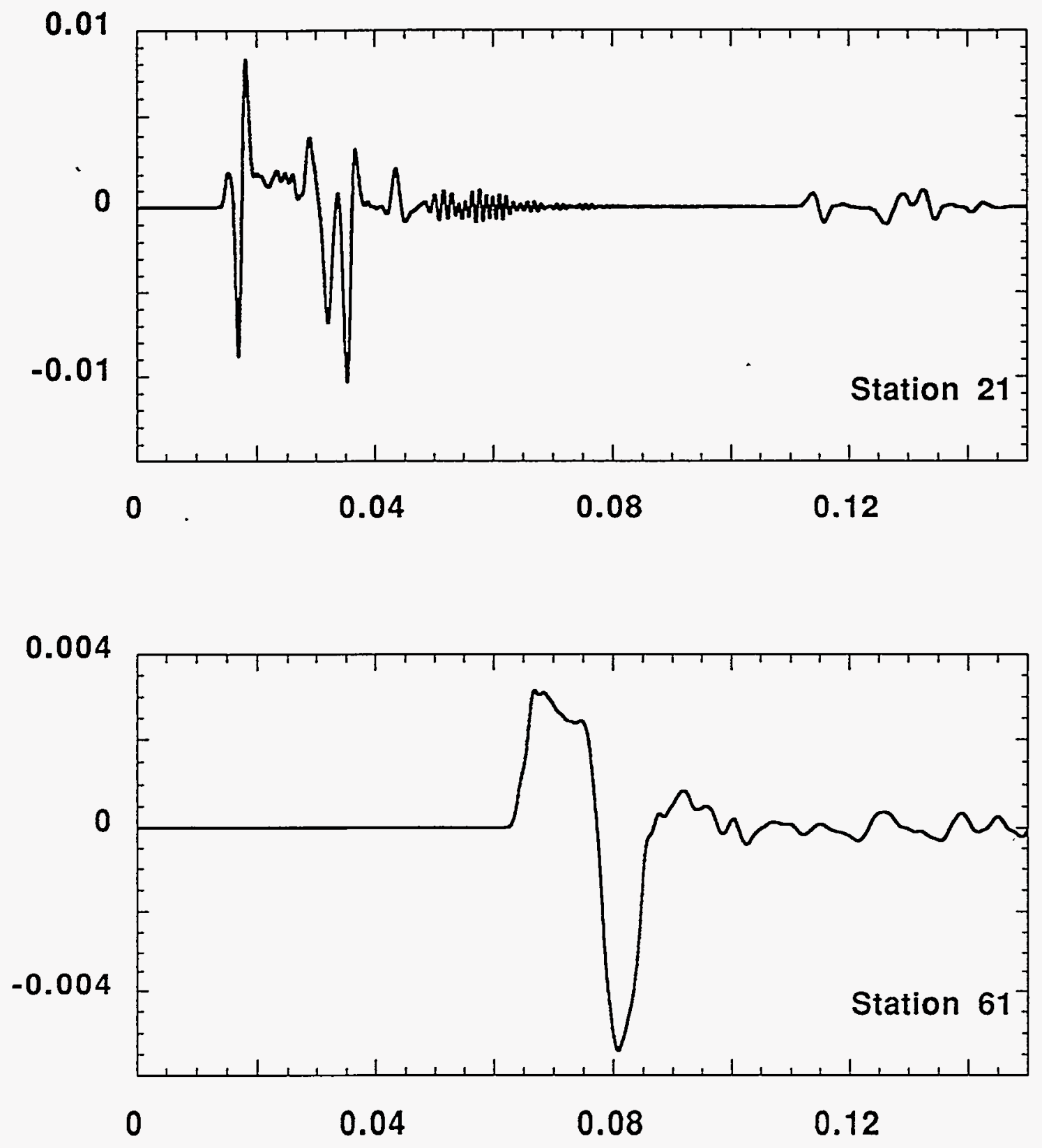

Fig 8: Calculated phase I radial velocities in $\mathrm{m} / \mathrm{s}$ versus time in seconds at 2 containment gage locations. Station 21 is $71 \mathrm{~m}$ downhole and station 61 is $15 \mathrm{~m}$ away from the borehole and $0.9 \mathrm{~m}$ below the surface. 

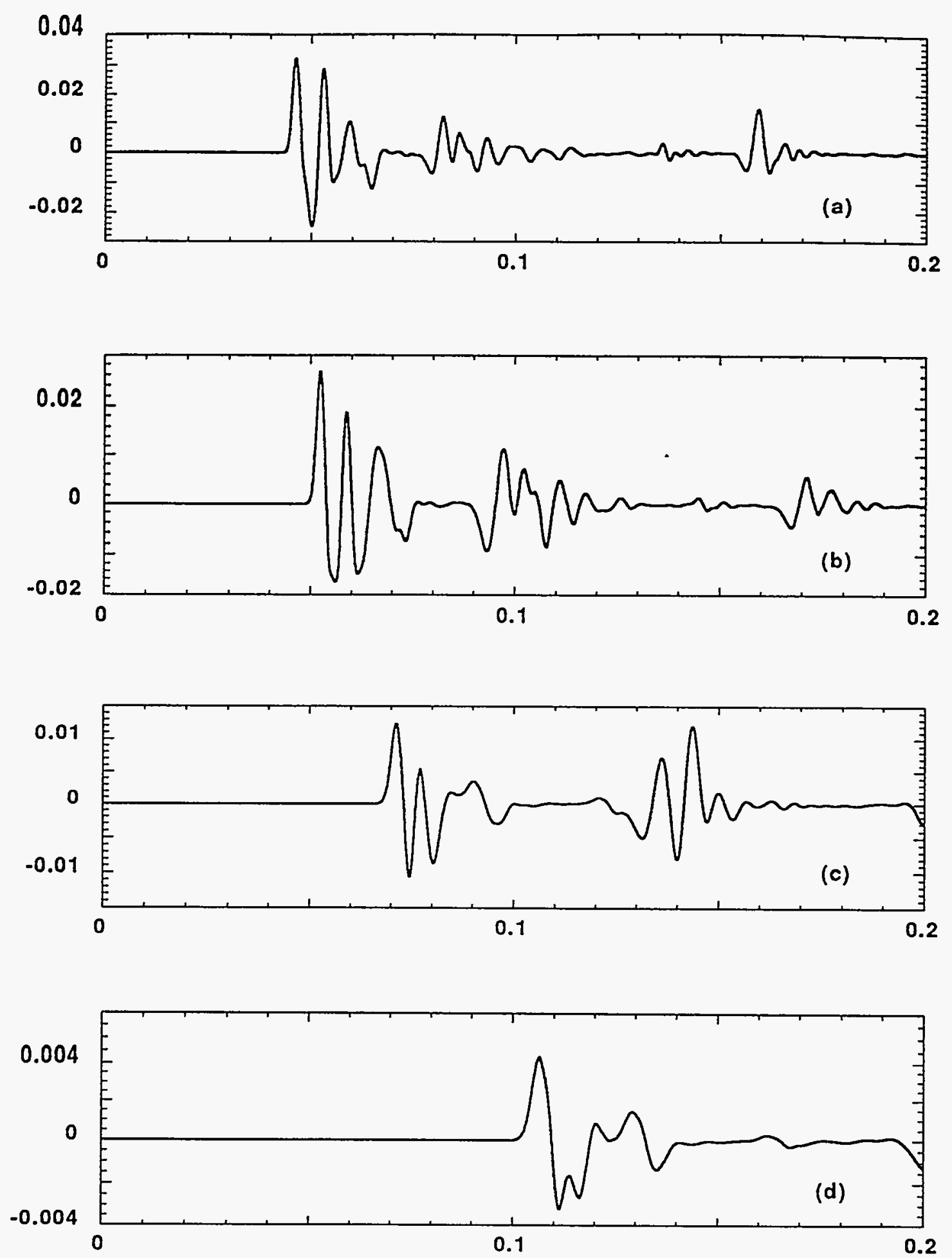

Fig 9: Calculated phase II axial velocities in $\mathrm{m} / \mathrm{s}$ versus time in seconds at 4 seismic gage locations on the surface. The distance from the gages to the drill hole is $20 \mathrm{~m}$ for a, $40 \mathrm{~m}$ for $\mathrm{b}, 80 \mathrm{~m}$ for $\mathrm{c}$, and $140 \mathrm{~m}$ for $\mathrm{d}$. 

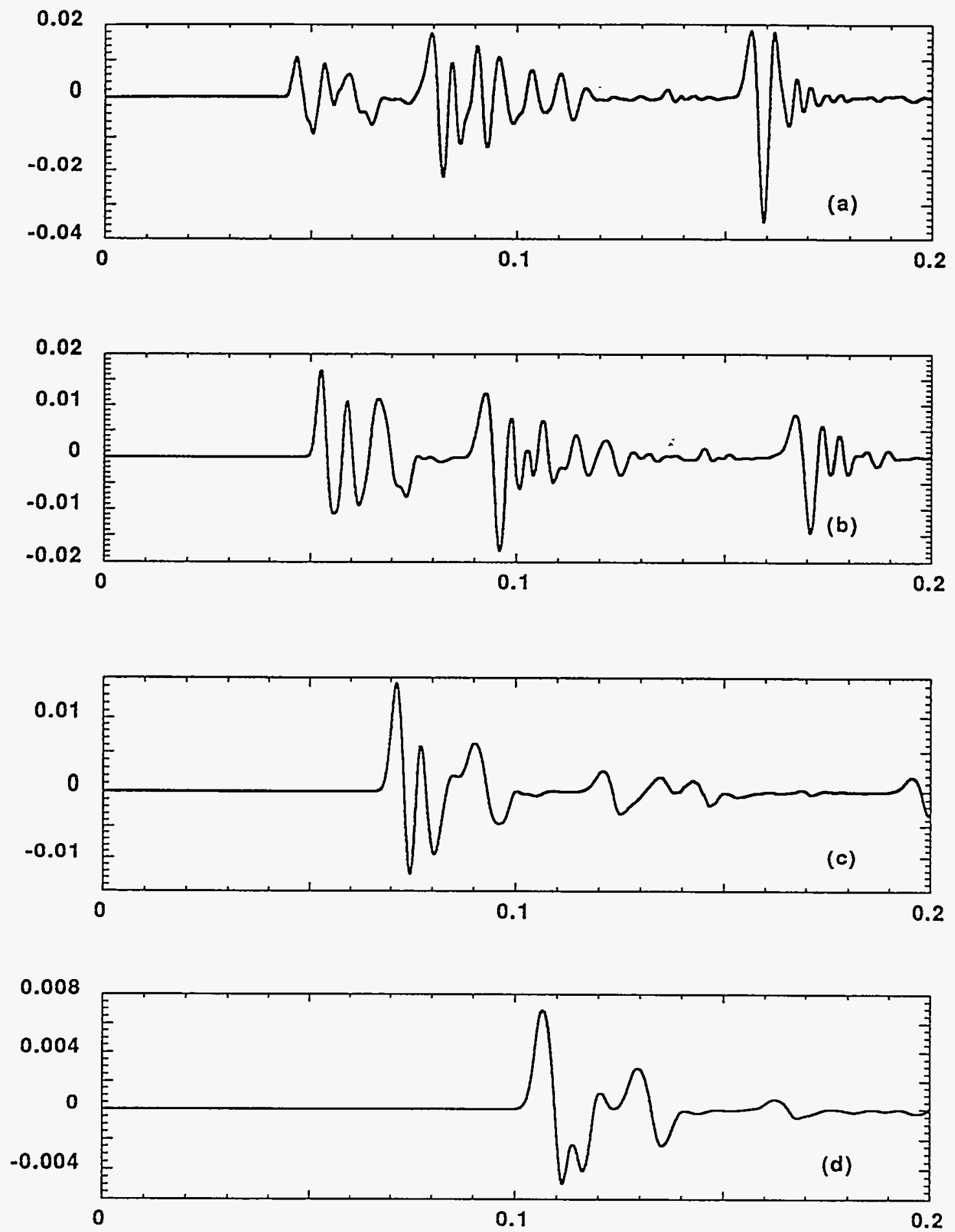

Fig 10: Calculated phase II radial velocities in $\mathrm{m} / \mathrm{s}$ versus time in seconds at 4 seismic gage locations on the surface. The distance from the gages to the drill hole is $20 \mathrm{~m}$ for a, $40 \mathrm{~m}$ for $\mathrm{b}, 80 \mathrm{~m}$ for $\mathrm{c}$, and $140 \mathrm{~m}$ for $\mathrm{d}$. 

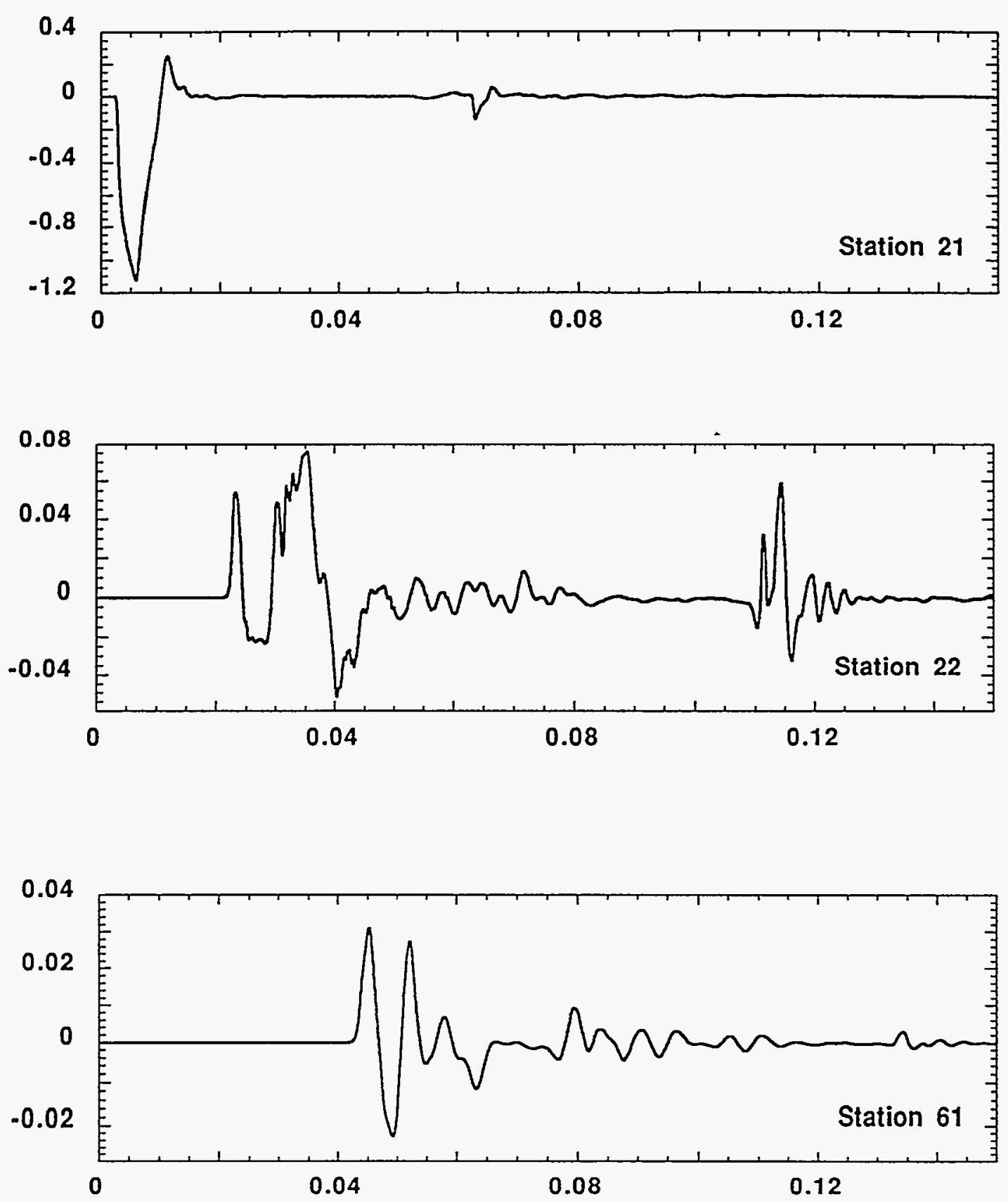

Fig 11: Calculated phase II axial velocities in $\mathrm{m} / \mathrm{s}$ versus time in seconds at 3 containment gage locations. Station 21 is $71 \mathrm{~m}$ downhole, station 22 is $30 \mathrm{~m}$ downhole, and station 61 is $15 \mathrm{~m}$ away from the borehole and $0.9 \mathrm{~m}$ below the surface. 

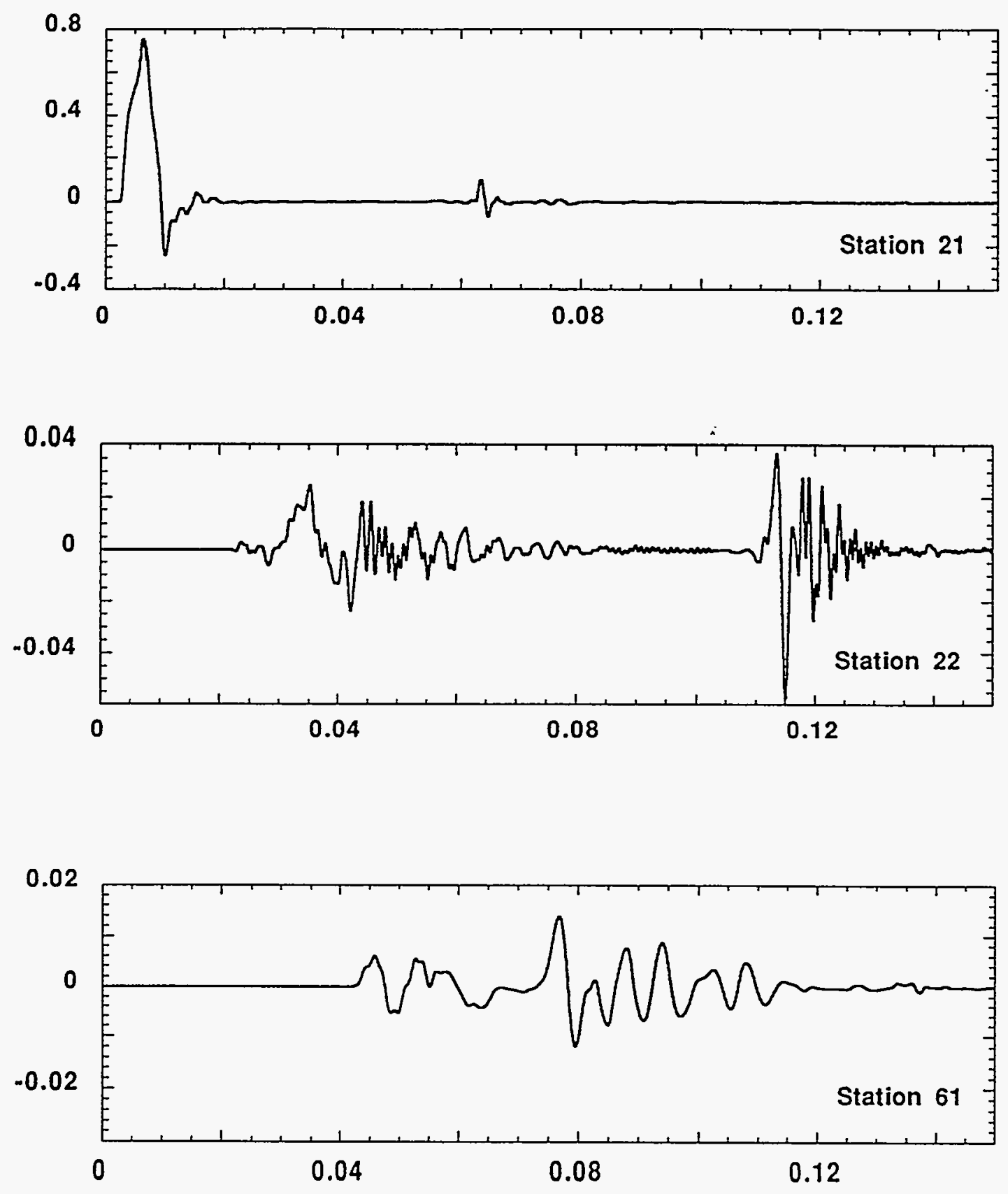

Fig 12: Calculated phase II radial velocities in $\mathrm{m} / \mathrm{s}$ versus time in seconds at 3 containment gage locations. Station 21 is $71 \mathrm{~m}$ downhole, station 22 is $30 \mathrm{~m}$ downhole, and station 61 is $15 \mathrm{~m}$ away from the borehole and $0.9 \mathrm{~m}$ below the surface. 


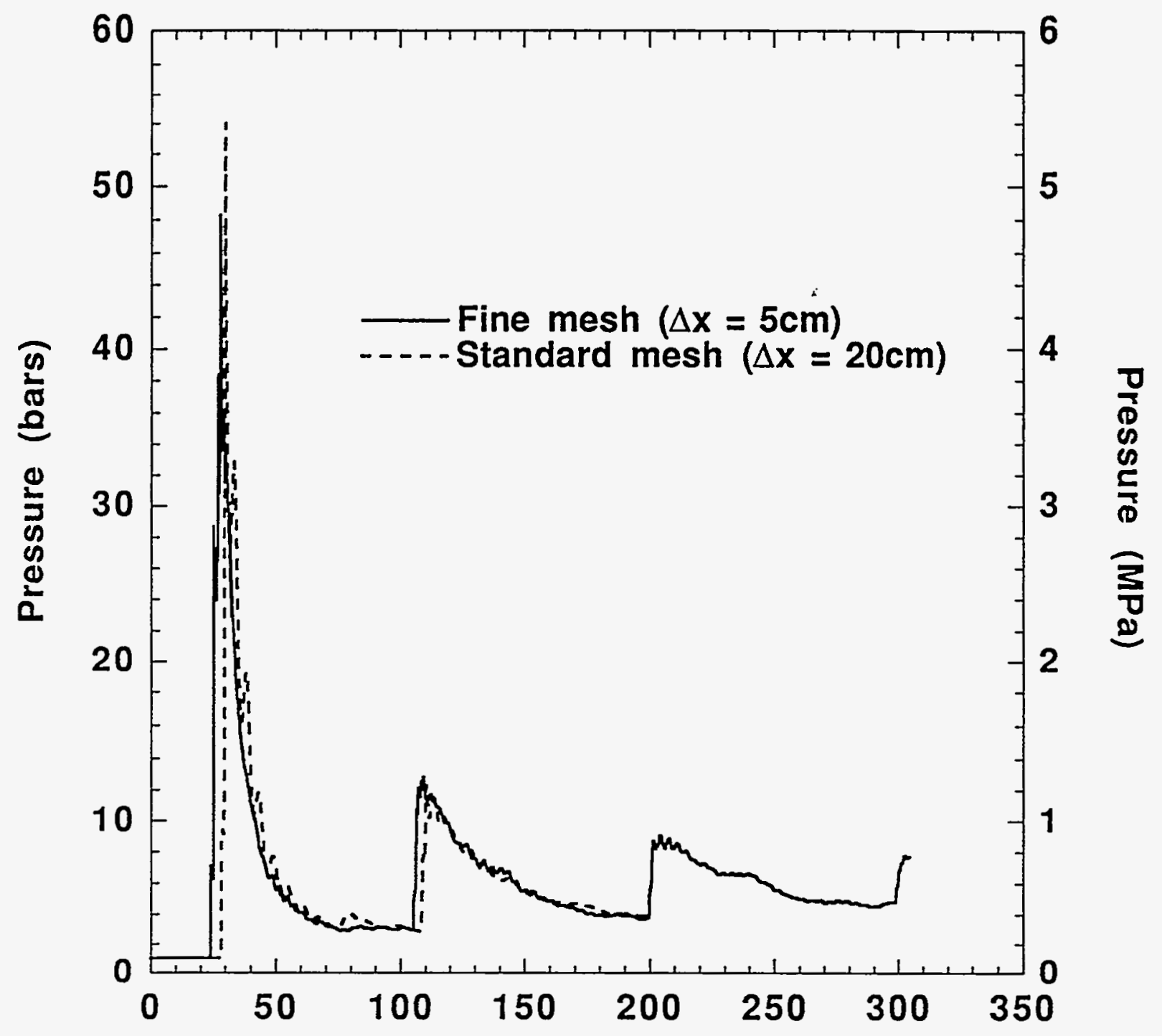

Time (ms)

Fig 13: Blast pressure $30 \mathrm{~cm}$ below the top of the cylindrical cavity. In the standard mesh, all the rock around the cavity was modeled. The fine mesh had only $1 \mathrm{~m}$ of rock around the cavity. 

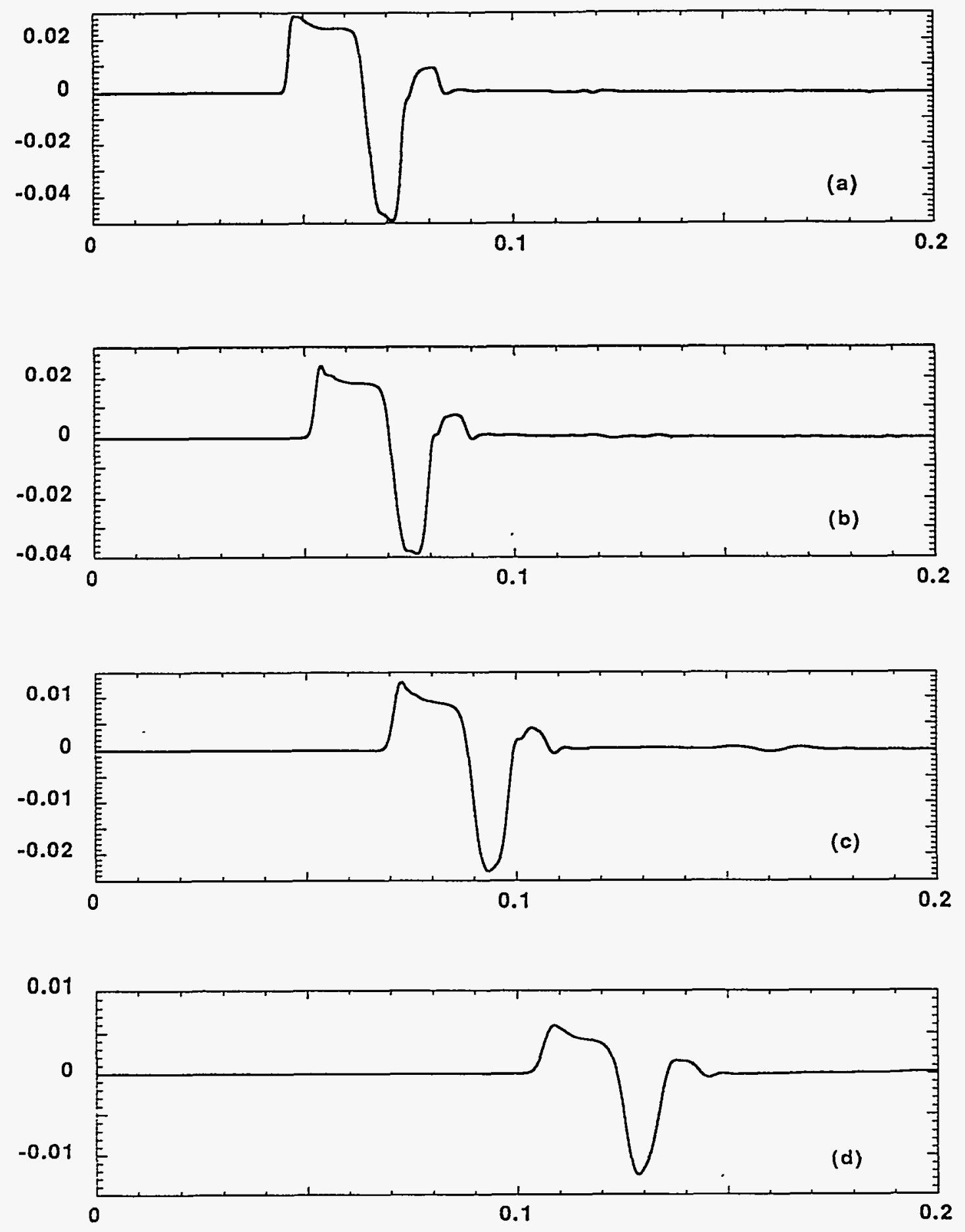

Fig 14: Calculated phase III axial velocities in $\mathrm{m} / \mathrm{s}$ versus time in seconds at 4 seismic gage locations on the surface. The distance from the gages to the drill hole is $20 \mathrm{~m}$ for a, $40 \mathrm{~m}$ for $\mathrm{b}, 80 \mathrm{~m}$ for $\mathrm{c}$, and $140 \mathrm{~m}$ for $\mathrm{d}$. 

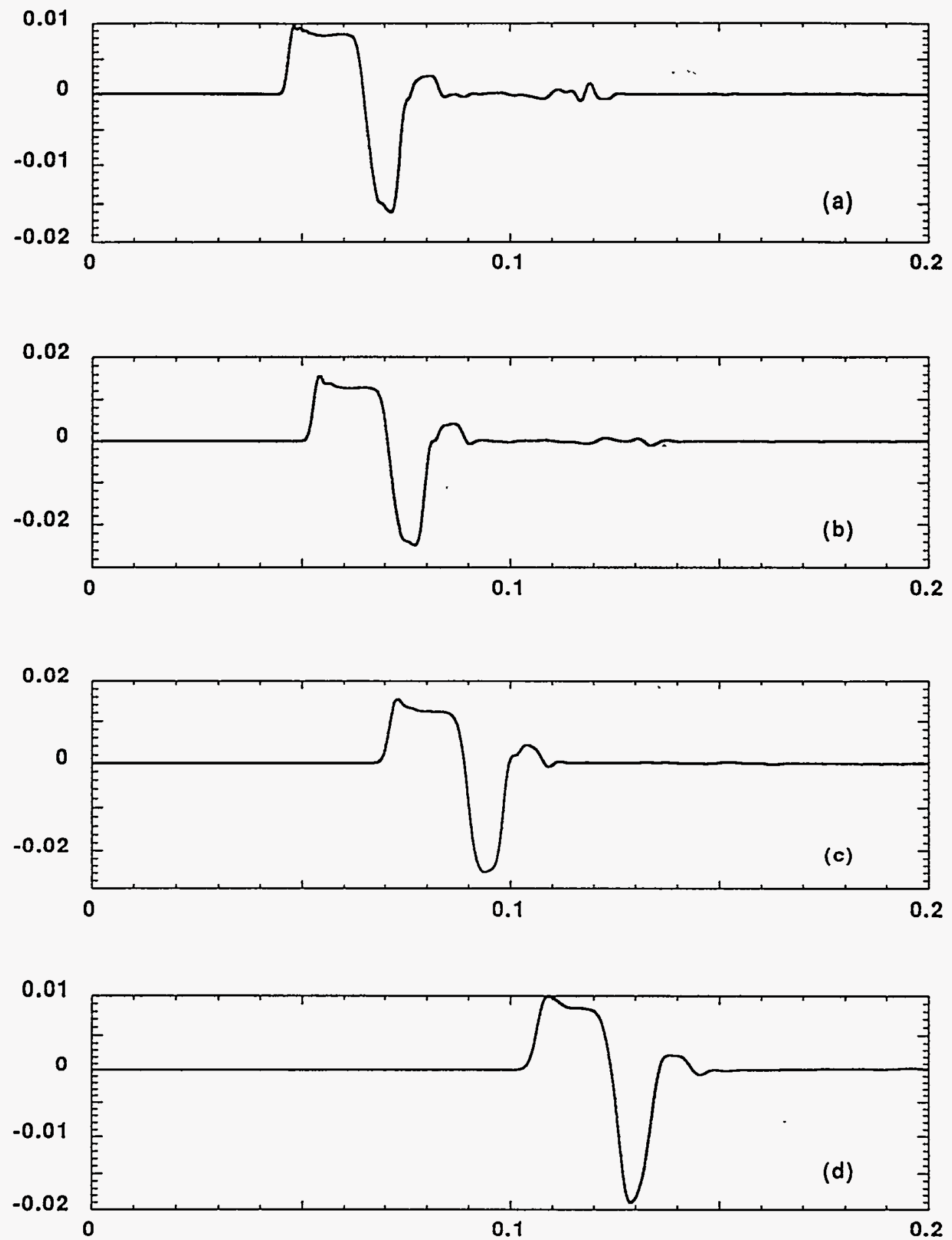

Fig 15: Calculated phase III radial velocities in $\mathrm{m} / \mathrm{s}$ versus time in seconds at 4 seismic gage locations on the surface. The distance from the gages to the drill hole is $20 \mathrm{~m}$ for a, $40 \mathrm{~m}$ for $\mathrm{b}, 80 \mathrm{~m}$ for $\mathrm{c}$, and $140 \mathrm{~m}$ for $\mathrm{d}$. 

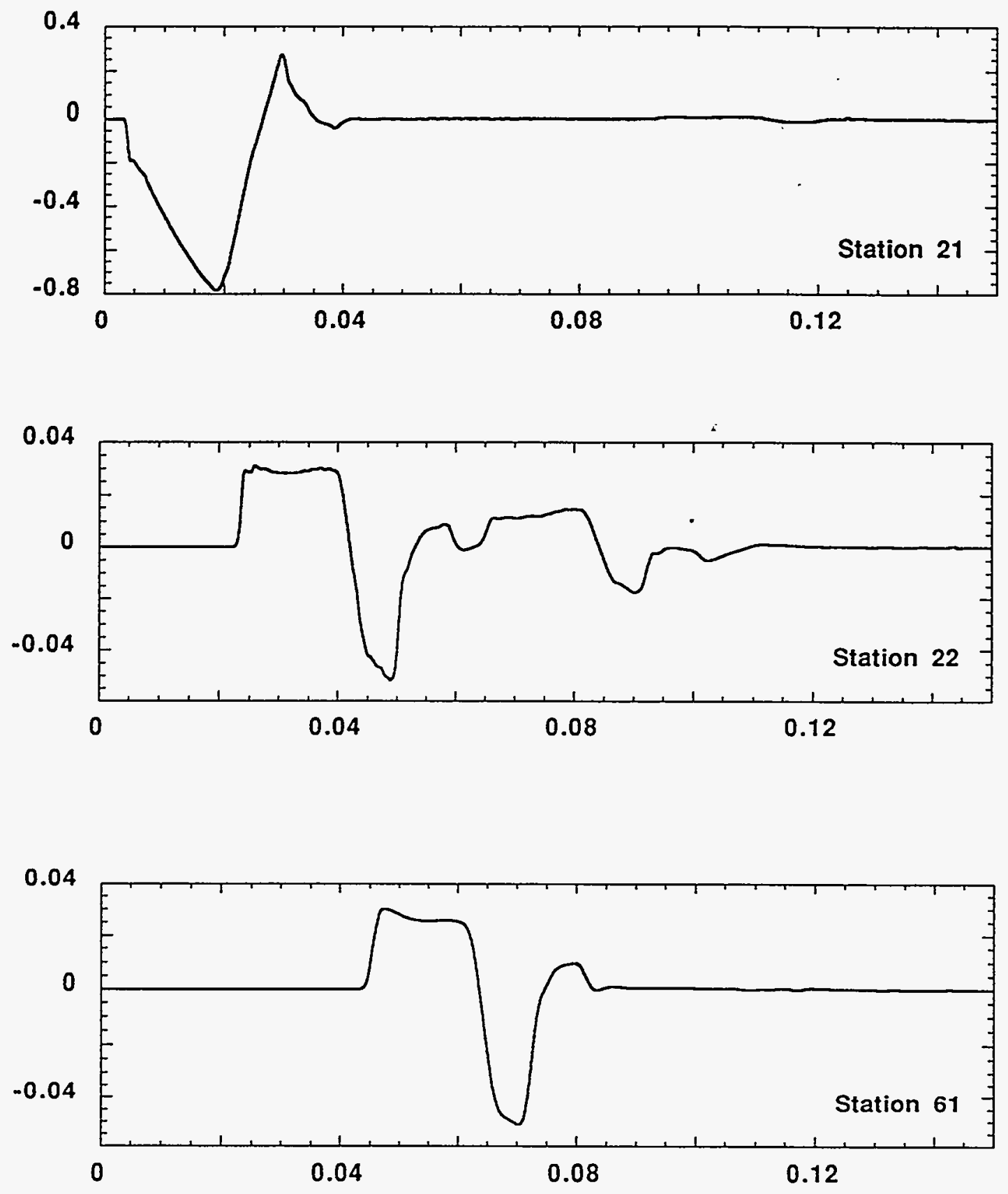

Fig 16: Calculated phase III axial velocities in $\mathrm{m} / \mathrm{s}$ versus time in seconds at 3 containment gage locations. Station 21

is $71 \mathrm{~m}$ downhole, station 22 is $30 \mathrm{~m}$ downhole, and station 61 is $15 \mathrm{~m}$ away from the borehole and $0.9 \mathrm{~m}$ below the surface. 

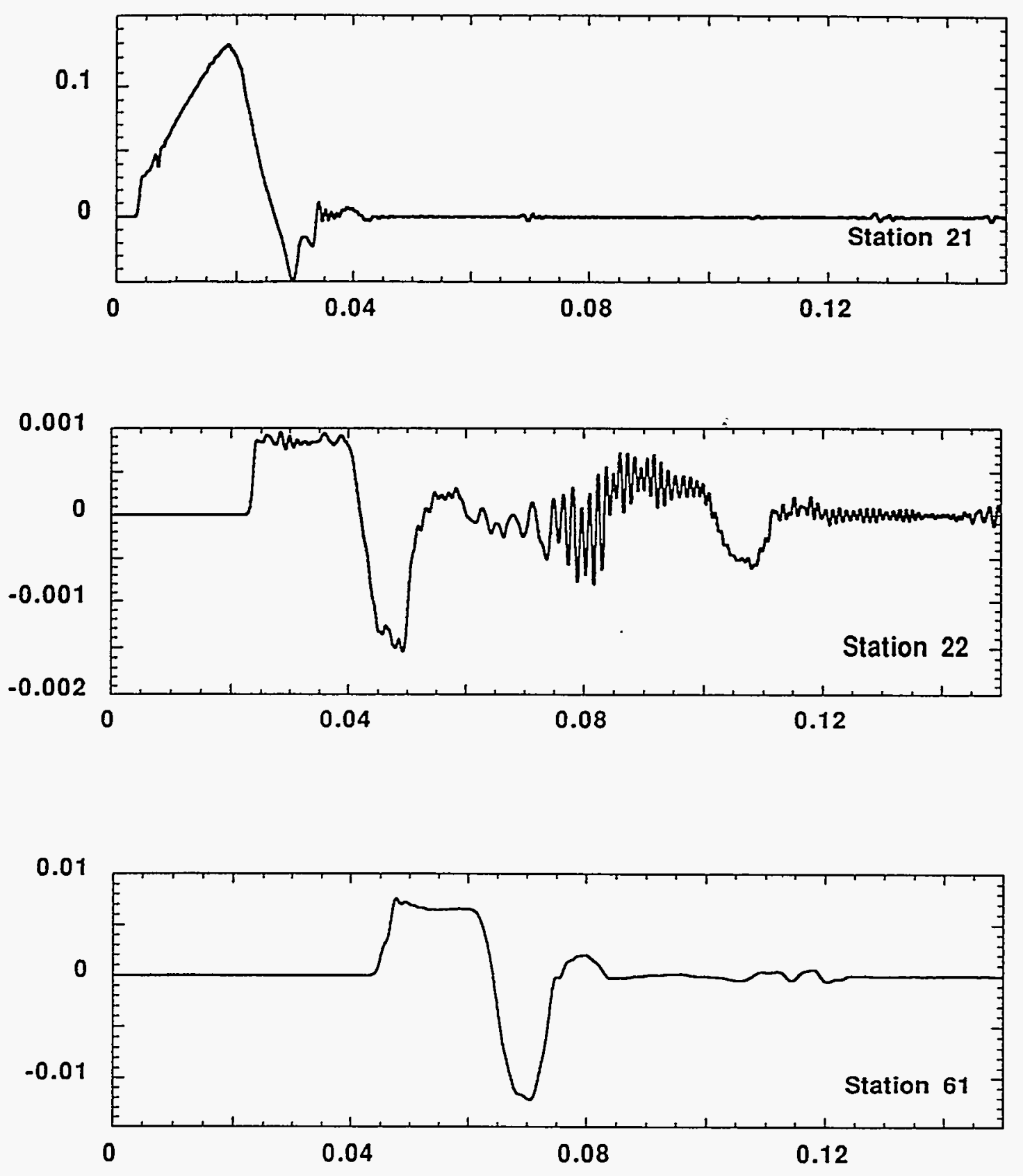

Fig 17: Calculated phase III radial velocities in $\mathrm{m} / \mathrm{s}$ versus time in seconds at 3 containment gage locations. Station 21 is $71 \mathrm{~m}$ downhole, station 22 is $30 \mathrm{~m}$ downhole, and station 61 is $15 \mathrm{~m}$ away from the borehole and $0.9 \mathrm{~m}$ below the surface. 


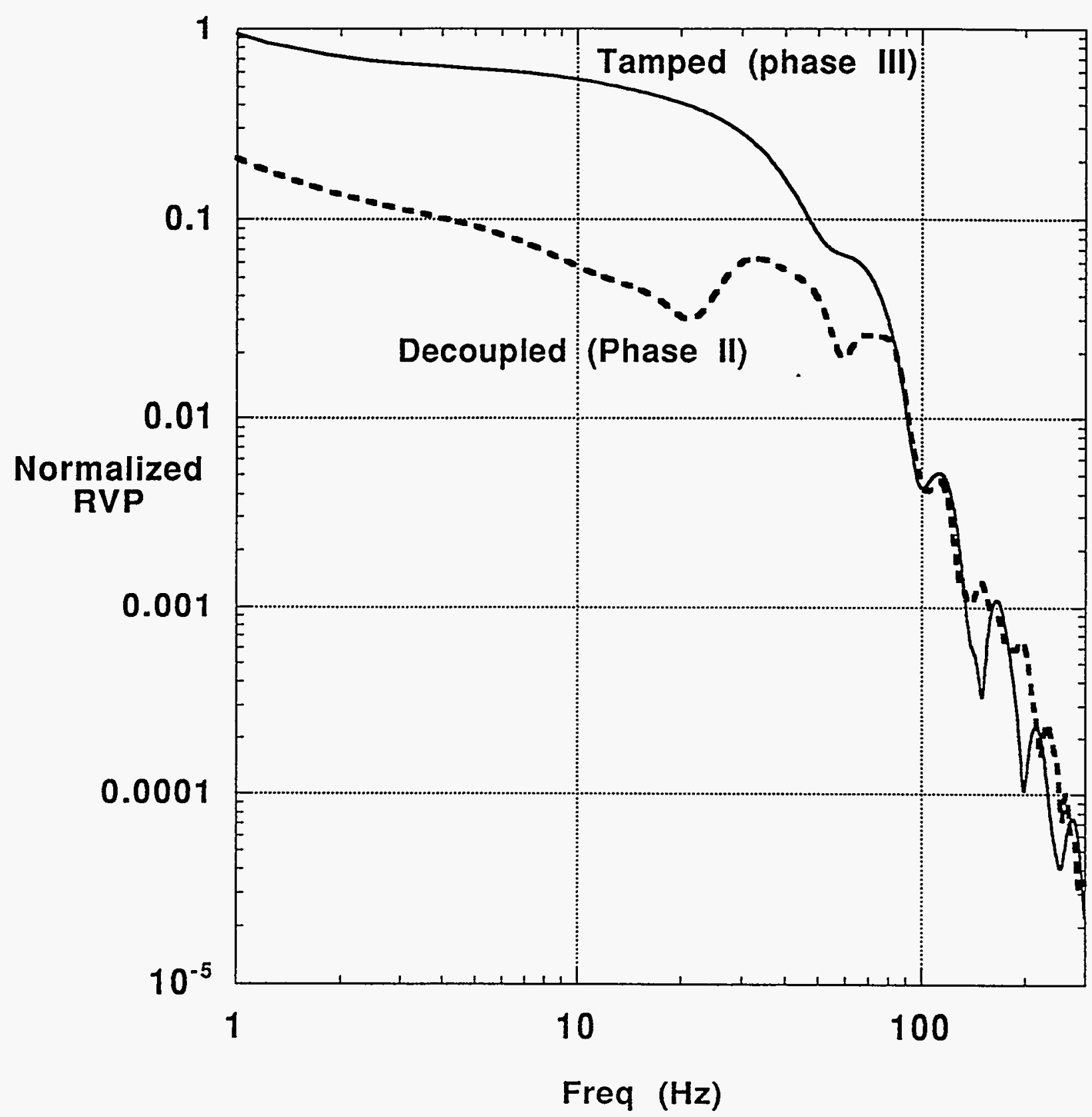

Fig 18: Reduced velocity potential (RVP) at a point on the surface $239 \mathrm{~m}$ away from the explosive. The RVP has been normalized so that it is equal to 1 for the tamped shot at 1 hertz 
